\title{
Immunohistochemical Localization of DARPP-32 in the Brain of Two Lungfishes: Further Assessment of Its Relationship with the Dopaminergic System
}

\author{
Jesús M. López Ruth Morona Agustín González \\ Departamento de Biología Celular, Facultad de Biología, Universidad Complutense, Madrid, Spain
}

\author{
Keywords \\ $\mathrm{D}_{1}$ receptor $\cdot$ Catecholamines $\cdot$ Dipnoans $\cdot$ Striatum . \\ Optic tectum $\cdot$ Brain evolution
}

\begin{abstract}
The distribution of DARPP-32 (a phosphoprotein related to the dopamine $D_{1}$ receptor) has been widely used as a means to clarify the brain regions with dopaminoceptive cells, primarily in representative species of tetrapods. The relationship between dopaminergic and dopaminoceptive elements is frequently analyzed using the catecholamine marker tyrosine hydroxylase (TH). In the present study, by means of combined immunohistochemistry, we have analyzed these relationships in lungfishes, the only group of sarcopterygian fishes represented by 6 extant species that are the phylogenetically closest living relatives of tetrapods. We used the Australian lungfish Neoceratodus forsteri and the African lungfish Protopterus dolloi. The DARPP-32 antibody yields a distinct and consistent pattern of neuronal staining in brain areas that, in general, coincide with areas that are densely innervated by TH-immunoreactive fibers. The striatum, thalamus, optic tectum, and torus semicircularis contain intensely DARPP-32-immunoreactive cell bodies and fibers. Cells are also located in the olfactory bulbs, amygdaloid complex, lateral septum, pallidum, preoptic area, suprachiasmatic nucleus, tuberal hypothalamic region, rostral
\end{abstract}

() 2017 S. Karger AG, Basel

\section{KARGER}

E-Mail karger@karger.com

www.karger.com/bbe rhombencephalic reticular formation, superior raphe nucleus, octavolateral area, solitary tract nucleus, and spinal cord. Remarkably, DARPP-32-immunoreactive fibers originating in the striatum reach the region of the dopaminergic cells in the mesencephalic tegmentum and represent a well-established striatonigral pathway in lungfishes. Double immunolabeling reveals that DARPP-32 is present in neurons that most likely receive TH input, but it is absent from the catecholaminergic neurons themselves, with the only exception of a few cells in the suprachiasmatic nucleus of Neoceratodus and the solitary tract nucleus of Protopterus. In addition, some species differences exist in the localization of DARPP-32 cells in the pallium, lateral amygdala, thalamus, prethalamus, and octavolateral area. In general, the present study demonstrates that the distribution pattern of DARPP-32, and its relationship with $\mathrm{TH}$, is largely comparable to those reported for tetrapods, highlighting a shared situation among all sarcopterygians.

(c) 2017 S. Karger AG, Basel

\section{Introduction}

Dopamine and cAMP-regulated phosphoprotein of relative molecular mass $32,000 \mathrm{Da}$ (DARPP-32) is a cytosolic protein that is phosphorylated by cAMP-dependent protein kinase (PKA) in response to the activation of the 
adenylyl-cyclase-coupled $\mathrm{D}_{1}$-dopamine receptor [Hemmings and Greengard, 1986; Greengard et al., 1998; Greengard, 2001; Yger and Girault, 2011]. It is also known as PPP1R1B (protein phosphatase 1, regulatory subunit $1 B$ ) because it is a potent inhibitor of protein phosphatase 1 (PP1) [Hemmings et al., 1984]. DARPP-32 was considered a good marker for neurons containing $\mathrm{D}_{1}$ receptor [Langley et el., 1997; Fienberg et al., 1998; Rajput et al., 2009], one of the main targets of dopamine, although it can be regulated by many other extracellular messengers, such as glutamate [Svenningsson et al., 2004; Fernández et al., 2006]. DARPP-32 is highly enriched in striatal medium-sized spiny neurons with a dense dopamine- and glutamate- innervation [Ouimet and Greengard, 1990; Walaas et al., 2011]. The activation of dopaminergic and glutamatergic receptors regulates the phosphorylation of DARPP-32, but with opposite molecular mechanisms. Thus, the stimulation of dopamine $\mathrm{D}_{1}$ receptor enhances the phosphorylation by PKA of Thr-34 site in DARPP-32 [Walaas et al., 1983; Walaas and Greengard, 1984], which acts as a strong PP1 inhibitor [Hemmings et al., 1984], whereas the activation of the NMDA receptor promotes the elevation of intracellular calcium, inducing dephosphorylation of DARPP-32 [Halpain et al., 1990; Nishi et al., 2005, 2017] and reducing its PP1 inhibitory activity. In addition, DARPP-32 is phosphorylated/dephosphorylated by several other kinases and phosphatases with multiple cellular responses, including the regulation of cytonuclear trafficking and chromatin response [Johansen and Johansen, 2006; Stipanovich et al., 2008; Yger and Girault, 2011]. Therefore, DARPP-32 acts as a "third messenger" that integrates multiple signaling pathways important to the proper functioning of the neural circuits in which it is expressed [Greengard et al., 1998; Svenningsson et al., 2002; Andersson et al., 2005; Kuroiwa et al., 2008; Hara et al., 2010; Yger and Girault, 2011].

Immunocytochemical studies using antibodies specific to DARPP-32 have been carried out to determine its regional and cellular distribution in the brain of representative mammalian species, and it was observed that this protein is localized primarily in those brain regions enriched in dopaminergic nerve terminals. Moreover, the staining pattern supports the conclusion that the DARPP-32 is present in dopaminoceptive neurons, i.e., neurons that receive a dopamine input, and that it is absent from the dopaminergic neurons themselves [Ouimet et al., 1984, 1992; Schalling et al., 1990]. In particular, the protein was primarily detected in the neostriatum [Ouimet et al., 1984, 1992; Gustafson and Greengard, 1990; Ouimet and Greengard, 1990; Anderson and Reiner, 1991; Barbas et al., 1993;
Greengard et al., 1998; Wang et al., 2004; Ishikawa et al., 2007; Glausier et al., 2010], and a striatal prevalence of the protein has been also confirmed in birds [Absil et al., 2001; Schnabel et al., 1997; Durstewitz et al., 1998; Reiner et al., 1998; Roberts et al., 2002; Bálint et al., 2004; Reiner et al., 2004; Metzger et al., 2006; Bálint and Csillag, 2007; Csillag et al., 2008]. In addition, studies in reptiles confirmed a pattern of distribution largely comparable among all amniotes [Smeets et al., 2001, 2003; Moreno et al., 2010]. In contrast, DARPP-32 was reported to be absent in anamniotes based on immunoblotting using antibodies against the bovine protein, and it was suggested that DARPP-32 evolved later during vertebrate evolution in the amniotes [Hemmings and Greengard, 1986]. However, subsequent phylogenetic studies comparing amino acid sequences of the PPP1R1/DARPP-32 family of PP1 inhibitors show that all members of this family are found in Osteichthyes (bony fishes, amphibians, reptiles, birds, and mammals) and seems to have originated in early vertebrate ancestors, probably in gnathostomes, whereas no homologous sequence was found in petromyzontoids (lampreys) and invertebrates [Yger and Girault, 2011]. Actually, DARPP-32 has been immunohistochemically mapped in the brain of anuran amphibians (anamniotes) and a largely common pattern of distribution with amniotes was observed [López et al., 2010; O'Connell et al., 2010]. Furthermore, a recent study has revealed the presence and distribution of DARPP-32 in the brain of the teleost zebrafish, although the pattern of distribution was noticeably different from tetrapods [Robra and Thirumalai, 2016]. However, it should be noted that the distribution of DARPP-32 reported in the zebrafish brain most likely cannot be taken as a full description of the DARPP-32-expressing cells. Actually, the absence of immunolabelling of DARPP-32 in many brain regions that otherwise exhibit other dopaminoceptive markers for the $\mathrm{D}_{1}$ receptor-bearing cells in teleosts [Kapsimali et al., 2000] suggests that this immunolabelling does not recapitulate the whole set of DARPP32-expressing cells in the zebrafish brain.

Living lungfishes (infraclass Dipnoi) are a small group of 6 species of sarcopterygian fishes with a great evolutionary interest because the current phylogenomic approaches strongly support lungfishes as the closest living relatives of amphibians and other tetrapods [Brinkmann et al., 2004; Takezaki et al., 2004; Chen et al., 2012; Amemiya et al., 2013; Biscotti et al., 2016]. Therefore, the study of the lungfish neuroanatomical organization is of special interest for deducing evolutionary traits that were conserved, modified, or lost in the transition from fishes to land vertebrates. 
Table 1. Summary of the distribution of DARPP-32-ir cells in different areas of the central nervous system of the main vertebrate groups studied

\begin{tabular}{|c|c|c|c|c|c|c|}
\hline & Teleost & Lungfishes & Amphibians & Reptiles & Birds & Mammals \\
\hline \multicolumn{7}{|l|}{ Forebrain } \\
\hline Olfactory bulb/olfactory tubercle & - & + & + & + & + & + \\
\hline Pallium/cortex & - & $+/-$ & $+/-$ & + & + & + \\
\hline Basal ganglia & - & + & + & + & + & + \\
\hline Septal region & - & + & + & + & + & + \\
\hline Amygdaloid complex & - & + & + & + & + & + \\
\hline Preoptic area & - & + & + & $+/-$ & + & + \\
\hline Paraventricular region & - & + & + & - & - & - \\
\hline Suprachiasmatic nucleus & - & + & + & - & - & - \\
\hline Tuberal hypothalamus & + & + & + & + & + & + \\
\hline Prethalamus & - & $+/-$ & $+/-$ & - & - & - \\
\hline Habenula & - & + & + & + & + & + \\
\hline Thalamus & - & $+/-$ & $+/-$ & + & + & - \\
\hline Pretectum & - & + & + & - & - & - \\
\hline \multicolumn{7}{|l|}{ Brainstem } \\
\hline Optic tectum/superior colliculus & + & + & + & + & + & - \\
\hline Torus semicircularis/inferior colliculus & - & + & + & + & + & - \\
\hline Mesencephalic tegmentum & - & - & + & - & - & - \\
\hline Isthmic nucleus/parabigeminal nucleus & - & - & - & + & - & - \\
\hline Cerebellum & + & - & $+/-$ & - & - & $+/-$ \\
\hline Reticular formation & - & + & + & - & + & - \\
\hline Octaval (octavolateral) area & + & + & $+/-$ & - & - & - \\
\hline Solitary tract/dorsal column nucleus & - & + & + & $+/-$ & - & - \\
\hline \multicolumn{7}{|l|}{ Spinal cord } \\
\hline Spinal gray matter & - & + & + & $+/-$ & - & $+/-$ \\
\hline
\end{tabular}

+, presence of DARPP-32-ir cells; -, absence of DARPP-32-ir cells; +/-, presence of DARPP-32-ir cells only in some species of the group. References: teleost: Robra and Thirumalai [2016]; lungfishes: González and Northcutt [2009]; present results; amphibians: López et al. [2010]; O'Connell et al. [2010]; reptiles: Smeets et al. [2001, 2003]; Moreno et al. [2010]; birds: Schnabel et al. [1997]; Durstewitz et al. [1998]; Reiner et al. [1998]; Absil et al. [2001]; Roberts et al. [2002]; Bálint et al. [2004]; Reiner et al. [2004]; Metzger et al. [2006]; Bálint and Csillag [2007]; Csillag et al. [2008]; mammals: Ouimet et al. [1984, 1992]; Ouimet and Greengard [1990]; Gustafson and Greengard [1990]; Anderson and Reiner [1991]; Perez and Lewis [1992]; Barbas et al. [1993]; Greengard et al. [1998]; Wang et al. [2004]; Ishikawa et al. [2007]; Glausier et al. [2010]; Buesa et al. [2016].

The catecholaminergic systems, and in particular the dopaminergic system, in lungfishes have been recently investigated by immunohistochemistry with antibodies against the rate-limiting enzyme of catecholamine synthesis, tyrosine hydroxylase (TH), and dopamine [López and González, 2017]. In the present study, we tried to further characterize these systems by evaluating the distribution pattern of DARPP-32, which will help in the identification of dopaminoceptive neuroanatomical structures. We have conducted a comprehensive analysis of the pattern of distribution of DARPP-32-immunoreactive (DARPP-32-ir) cells and fibers in the central nervous sys- tem of 2 representative species of lungfishes belonging to the 2 extant orders, the Australian lungfish Neoceratodus forsteri and the African lungfish Protopterus dolloi, using the same techniques applied in other studies in tetrapods. In addition, we investigated the correlative locations of dopaminergic (TH immunoreactive; TH-ir) and dopaminoceptive (DARPP-32 containing) structures in the brain using double immunohistofluorescence techniques. The analysis of the results in lungfishes and their comparison with those obtained in other vertebrate groups (Table 1), will serve to establish primitive and derived traits in the DARPP-32 system. 


\section{Materials and Methods}

For the present study, a total of 3 juvenile Australian lungfish $N$. forsteri (total length $35-42 \mathrm{~cm}$ ) and 5 juvenile African lungfish $P$. dolloi (total length $21-30 \mathrm{~cm}$ ) were used. The African lungfish were purchased from an authorized commercial supplier (PezyCia, Madrid, Spain), and the Australian lungfish were obtained from Jindalee International Pty Ltd (Milton, QLD, Australia), an approved breeder and exporter. All animals were maintained in aquaria at $24-28^{\circ} \mathrm{C}$ under natural light conditions. The original research reported herein was performed according to the regulations and laws established by European Union (2010/63/EU) and Spain (Royal Decree 53/2013) after approval from the Universidad Complutense to conduct the experiments described. In addition, the $N$. forsteri specimens were handled by Dr. Glenn R. Northcutt and the initial steps of perfusion and fixation (the brains were then shipped to Spain) were conducted in the USA in conformation with standards established by the Institutional Animal Care and Use Committee at the University of California (San Diego) for the care and handling of animals in research.

The animals were deeply anesthetized by immersion in $0.01 \%$ tricaine methanesulfonate solution (MS222, Sandoz Basel, SW; pH 7.3) and perfused transcardially with physiological saline followed by $200 \mathrm{~mL}$ of cold $4 \%$ paraformaldehyde in a 0.1 -M phosphate buffer ( $\mathrm{PB} ; \mathrm{pH}$ 7.4). The brain and the upper spinal cord were removed from the skulls and kept in the same fixative for $2-3 \mathrm{~h}$. Subsequently, they were immersed in a solution of $30 \%$ sucrose in PB for $4-6 \mathrm{~h}$ at $4^{\circ} \mathrm{C}$ until they sank, then embedded in a solution of $20 \%$ gelatin with $30 \%$ sucrose in $\mathrm{PB}$, and stored for $6 \mathrm{~h}$ in a $3.7 \%$ formaldehyde solution at $4{ }^{\circ} \mathrm{C}$. The brains were cut on a freezing microtome at $40 \mu \mathrm{m}$ in the transverse plane, and sections were collected and rinsed in cold PB.

\section{DARPP-32 Immunohistochemistry}

The free-floating sections were rinsed twice in $\mathrm{PB}$, treated with $1 \% \mathrm{H}_{2} \mathrm{O}_{2}$ in $\mathrm{PB}$ for 15 min to reduce endogenous peroxidase activity, rinsed again 3 times in $\mathrm{PB}$, and processed by the peroxidase antiperoxidase (PAP) method [Sternberger, 1979]. This included a first incubation of the sections in a primary serum of mouse anti-DARPP-32 (kindly donated by Dr. H.C. Hemmings Jr., The New York Hospital, Cornell Medical Center, NY, USA) diluted $1: 10,000$ in PB containing $0.5 \%$ Triton $\mathrm{X}-100,15 \%$ normal rabbit serum, and $2 \%$ bovine serum albumin, for $48 \mathrm{~h}$ at $4{ }^{\circ} \mathrm{C}$. Subsequently, the sections were rinsed 3 times in $\mathrm{PB}$ for $10 \mathrm{~min}$ and incubated for $60 \mathrm{~min}$ at room temperature in rabbit antimouse serum (Chemicon, Temecula, CA, USA; catalogue reference AP160) diluted 1:50. After rising again 3 times for $10 \mathrm{~min}$, the sections were incubated for $90 \mathrm{~min}$ in mouse PAP complex (Chemicon; catalogue reference PAP14) diluted 1:500. Secondary antiserum and PAP complex were diluted in PB containing $0.5 \%$ Triton $\mathrm{X}-100,15 \%$ normal rabbit serum, and $2 \%$ bovine serum albumin. Finally, the sections were rinsed 3 times for 10

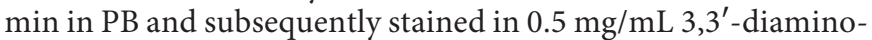
benzidine (DAB; Vector SK4100) intensified with nickel [Adams et al., 1981], with $0.01 \% \mathrm{H}_{2} \mathrm{O}_{2}$ in $\mathrm{PB}$ for 5-10 $\mathrm{min}$. The series were mounted on glass slides with $0.25 \%$ gelatin in $0.1 \mathrm{M}$ Tris- $\mathrm{HCl}$ buffer (TB, pH 7.6) and, after dehydration, coverslipped with Entellan (Merck, Darmstadt, Germany). Some sections were counterstained with cresyl violet to facilitate analysis of the results.
The specificity of the antisera was tested previously [Hemmings and Greengard, 1986] and it has been used in immunohistochemical studies in tetrapods [Ouimet et al., 1992; Schnabel et al., 1997; Reiner et al., 1998; Smeets et al., 2001, 2003; López et al., 2010; Moreno et al., 2010]. In addition, the immunohistochemical reaction was corroborated with controls in which either the primary antibody, secondary antibody, or the PAP complex was omitted. In all these negative controls, the immunostaining was eliminated.

\section{Double DARPP-32 and TH Immunohistochemistry}

To analyze the possible interactions between the DARPP-32-ir elements with the catecholaminergic structures a procedure based on double immunolabeling was used as follows: (1) first incubation for $48 \mathrm{~h}$ at $4{ }^{\circ} \mathrm{C}$ in a mixture of mouse anti-DARPP-32 (diluted 1:10,000) and rabbit anti-TH (diluted 1:500; Millipore; catalogue reference AB152); (2) second incubation for 90 min at room temperature in a mixture of secondary antibodies: Alexa 488-conjugated goat anti-mouse (green fluorescence; Molecular Probes, Eugene, OR, USA; catalogue reference A21042) and Alexa 594-conjugated goat anti-rabbit (red fluorescence; Molecular Probes; catalogue reference A11037), both diluted 1:500. After rising 3 times in $\mathrm{PB}$, the sections were mounted on glass slides and coverslipped with Vectashield (Vector, Burlingame, CA, USA).

The specificity of the TH antibody was recently assessed in lungfishes [López and González, 2017] and the immunostaining obtained in this study corroborated the correspondence between the immunohistochemical staining patterns obtained with this antiserum and other commercial monoclonal antibodies [González and Northcutt, 2009; López et al., 2009, 2012; López and González, 2017]. It should be noted that in vertebrates, 2 distinct TH genes exist, $\mathrm{TH} 1$ and $\mathrm{TH} 2$, and the $\mathrm{TH} 2$ gene appears to have been lost in evolution only in placental mammals [see Yamamoto and Vernier, 2011]. Most commercially available antibodies to TH, including the one used in this study, were prepared against mammalian $\mathrm{TH}$ epitopes and only recognize $\mathrm{TH} 1$, which is expressed in the vast majority of catecholaminergic neurons [for more information, see López and González, 2017].

\section{Western Blotting Analysis}

Western blotting analysis was performed for further characterization of the DARPP-32 antibody in lungfishes, and to test the consistency of the staining across species. One animal of each lungfish species was anesthetized, and the brains and spinal cords were quickly removed and frozen in dry ice until use. They were homogenized in homogenization buffer ( 5 mM EDTA, 20 mM Tris, $\mathrm{pH}$ 7.4, $150 \mathrm{~mm} \mathrm{NaCl}, 10 \%$ glycerol, 1\% Nonidet P40; Roche, Mannheim, Germany) supplemented with protease and phosphatase inhibitors $(50 \mu \mathrm{g} / \mathrm{mL}$ phenylmethylsulfonyl fluoride, $10 \mu \mathrm{g} /$ $\mathrm{mL}$ aprotinin, $25 \mu \mathrm{g} / \mathrm{mL}$ leupeptin, and $100 \mathrm{nM}$ orthovanadate; all from Sigma). The supernatant, which included $50 \mu \mathrm{g}$ of protein, was applied in each lane of $12 \%$ polyacrylamide (No. 161-0801; Bio-Rad) gel and separated by SDS-PAGE with a Mini-Protean system (Bio-Rad). Similarly obtained samples of the whole brain of the amphibian Xenopus laevis, the reptilian Pseudemys scripta, and the rat were run in other lanes, as well as molecular weight standards (Precision Plus Protein Kaleidoscope Standards, Bio$\mathrm{Rad})$. The separated samples in the gel were transferred to nitrocellulose membrane (Bio-Rad). Nonspecific binding sites were blocked by incubation overnight in Tris- $\mathrm{HCl}$ buffer (TBS) con- 
taining $0.1 \%$ Tween- 20 and $5 \%$ nonfat milk, at $4^{\circ} \mathrm{C}$. The blots were then incubated for $24 \mathrm{~h}$ at $4^{\circ} \mathrm{C}$ in primary antibody dilution (as for immunohistochemistry). After 3 washes in TBS (10 min each), the membranes were incubated with goat anti-mouse horseradish peroxidase-coupled secondary antibody (Jackson ImmunoResearch Laboratories Inc., West Grove, PA, USA; diluted 1:15,000) for $2 \mathrm{~h}$ at room temperature. Immunoreactive bands were detected by using an enhanced chemiluminescence system (Super Signal West Pico Chemiluminiscent Substrate, Pierce, Thermo Scientific, Rockford, IL, USA). Photographs were taken after applying an autoradiographic film to the membrane, in the darkness, for 1-4 min (Fig. 1).

\section{Evaluation and Presentation of the Results}

The distribution of DARPP-32-ir cell bodies and fibers in the brains of Protopterus and Neoceratodus was carefully analyzed with an Olympus BX51 microscope equipped with the appropriate filters for green-red fluorescence. The rostrocaudal distribution of DARPP-32-ir cell bodies and fibers was charted in representative transverse sections for the case of $N$. forsteri (Fig. 2). Drawings were made by means of a camera lucida in which the sections counterstained with cresyl violet facilitated the interpretation of the localization of the labeled structures. Selected photomicrographs of single-labeled (Fig. 3-5) or double-labeled (Fig. 6-8) sections were obtained with a digital camera (Olympus DP70). Contrast and brightness were adjusted in Adobe PhotoShop CS3 (Adobe System, San Jose, CA, USA) and the photographs were mounted on figures in Canvas 11 (ACS System International).

The precise localization of the labeled structures was framed within the newly defined territories in the telencephalon of lungfishes [González and Northcutt, 2009], the segmental model proposed for the prosencephalon [Puelles and Rubenstein, 2003, 2015] and the rhombencephalon, adapted for lungfishes [see López et al., 2017]. The nomenclature used is essentially the same as followed in our previous studies of lungfish brains [González and Northcutt, 2009; López et al., 2012, 2017; López and González, 2015, 2017].

\section{Results}

The antibody against DARPP-32 used in the present study revealed patterns of immunoreactivity that, for each of the 2 species examined, were constant from animal to animal. The labeling observed was restricted to neuronal cell bodies and fibers located in all main brain divisions. Additionally, the double DARPP-32/TH immunolabeling techniques allowed the analysis of possible colocalization/codistribution of both proteins and the relationship between the catecholaminergic innervation and DARPP-32-ir cell populations. Together with the immunohistochemical techniques, immunoblotting was used to analyze the presence of DARPP-32 in the brain of lungfishes. The Western blots of brain extracts of each species showed that the anti-DARPP-32 antiserum labeled single bands between 30 and $32 \mathrm{kDa}$ that corre-

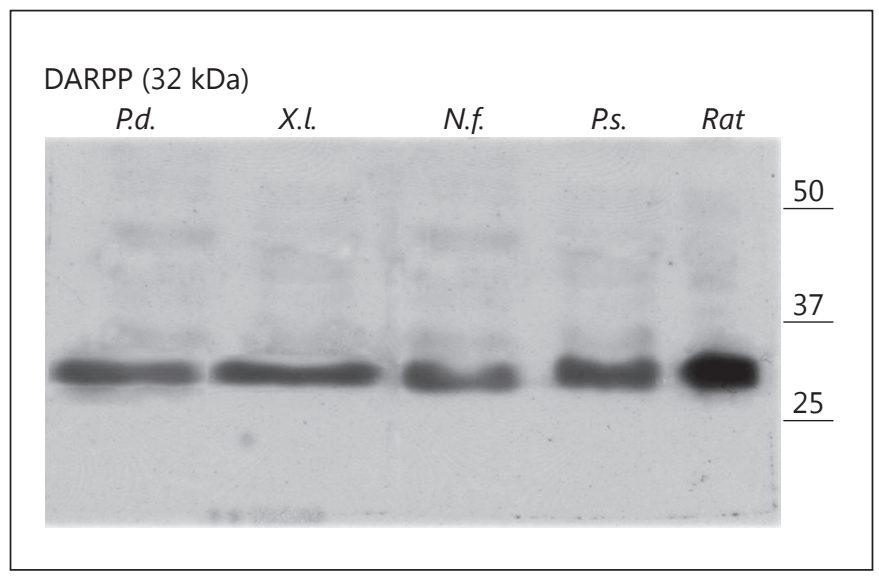

Fig. 1. Identification by Western blot of protein bands recognized for the mouse anti-DARPP-32 antibody. A single band is seen in each of the lines corresponding to the lungfish brain extracts (P.d., P. dolloi; N.f., N. forsteri) that are compared with the band stained for amphibian (X.l., X. laevis), reptile (P.s., P. scripta), and rat brain extracts. The expected molecular weight is indicated for this protein, and the molecular weight standard is represented on the right of the photograph.

spond well with the bands labeled in the rat, X. laevis, and P. scripta lanes (Fig. 1). However, using the Western blot analysis it is difficult to assess whether the antibody recognizes the same protein or merely proteins with similar molecular weights. Therefore, it can be considered that we are detecting DARPP-32-like immunoreactive structures, but for simplicity we will refer to DARPP-32-ir cell bodies and fibers.

The regional distribution of DARPP-32-ir cell bodies and fibers was charted for $N$. forsteri in Figure 2. In the following, we describe the distribution of the DARPP32 -ir elements taking Neoceratodus as the core species for which the complete pattern is detailed, but including the differential results obtained in Protopterus in specific brain regions. In both species, widespread immunoreactive structures were localized in all brain subdivisions and will be described from rostral to caudal levels.

\section{Forebrain}

The telencephalon of lungfishes is formed by 2 large evaginated hemispheres. In the case of Neoceratodus the ventral region or subpallium is markedly bigger than the dorsally located pallium, which is partially reduced to an ependymal tela (Fig. 2b-d, 3a). The olfactory bulbs are connected by a short peduncle to the rostral pole of the hemisphere (see the lateral view of the brain in Fig. 2). The subpallium of Protopterus is also very large and con- 


\begin{tabular}{|c|c|c|c|}
\hline a & cerebellar auricle & Nsol & nucleus of the solitary tract \\
\hline $\mathrm{AP}$ & area postrema & $\mathrm{ob}$ & olfactory bulb \\
\hline BST & bed nucleus of the stria terminalis & oc & optic chiasm \\
\hline $\mathrm{Cb}$ & cerebellum & $\mathrm{OT}$ & optic tectum \\
\hline $\mathrm{cc}$ & central canal & $\mathrm{Pa}$ & paraventricular area \\
\hline $\mathrm{CeA}$ & central amygdala & $\mathrm{PA}$ & pallidum \\
\hline $\mathrm{cn}$ & cerebellar nucleus & $\mathrm{pc}$ & posterior commissure \\
\hline co & caudal octavolateral nucleus & POA & preoptic area \\
\hline $\mathrm{CoP}$ & commissural pretectal region & $\mathrm{PT}$ & pretectum \\
\hline DF & dorsal funiculus & PTh & prethalamus \\
\hline $\mathrm{dh}$ & dorsal horn of spinal cord & Ram & median raphe nucleus \\
\hline do & dorsal octavolateral nucleus & Ras & superior raphe nucleus \\
\hline $\mathrm{Dp}$ & dorsal pallium & $\mathrm{Ri}$ & inferior reticular nucleus \\
\hline flm & fasciculus longitudinalis medialis & $\mathrm{Rm}$ & median reticular nucleus \\
\hline fr & fasciculus retroflexus & $\mathrm{RM}$ & retromammary region \\
\hline gl & glomerular layer & Rs & superior reticular nucleus \\
\hline $\mathrm{Hb}$ & habenula & SCc & suprachiasmatic nucleus, caudal part \\
\hline Hyp & hypophysis & $\mathrm{SCr}$ & suprachiasmatic nucleus, rostral part \\
\hline igl & internal granular layer of the olfactory bulb & Smn & somatomotor neurons of the spinal cord \\
\hline Ipn & interpeduncular neuropile & sol & solitary tract \\
\hline Is & isthmic nucleus & Str & striatum \\
\hline LA & lateral amygdala & Tegm & mesencephalic tegmentum \\
\hline Lc & locus coeruleus & $\mathrm{Th}$ & thalamus \\
\hline LDT & laterodorsal tegmental nucleus & Tor & torus semicircularis \\
\hline LF & lateral funiculus & $\mathrm{TP}$ & nucleus of the posterior tubercle \\
\hline lfb & lateral forebrain bundle & $\mathrm{Tu}$ & tuberal hypothalamus \\
\hline $\mathrm{Lp}$ & lateral pallium & $\mathrm{v}$ & ventricle \\
\hline Ls & lateral septum & $\mathrm{Vd}$ & descending trigeminal nucleus \\
\hline lvctel & ventrocaudal telencephalic lobe & VF & ventral funiculus \\
\hline M & mamillary nucleus & $\mathrm{vh}$ & ventral horn of the spinal cord \\
\hline $\mathrm{MCa}$ & Mauthner cell axon & $\mathrm{Vp}$ & principal trigeminal sensory nucleus \\
\hline $\mathrm{MeA}$ & medial amygdala & $\mathrm{Vr}$ & ventral thalamic nucleus, rostral part \\
\hline $\mathrm{ml}$ & mitral layer & VTA/SN & ventral tegmental area/substantia nigra complex \\
\hline mo & medial octavolateral nucleus & III & oculomotor nucleus \\
\hline $\mathrm{Mp}$ & medial pallium & IV & trochlear nucleus \\
\hline MPO & median preoptic nucleus & $\mathrm{Vm}$ & trigeminal motor nucleus \\
\hline Ms & medial septum & IXm & glossopharyngeal motor nucleus \\
\hline $\mathrm{NPv}$ & nucleus of the periventricular hypothalamic organ & $\mathrm{Xm}$ & vagal motor nucleus \\
\hline
\end{tabular}

tains a caudal protrusion named the ventrocaudal telencephalic lobe (lvctel, Fig. 5d). The pallium is thick at all levels and the olfactory bulbs lack peduncles and are sessile on the rostral part of the hemisphere.

The olfactory bulbs in both species show all cell types present in most vertebrates, as well as a laminar arrangement with granular, mitral, and glomerular cell layers separated by plexiform layers [Nieuwenhuys, 1998]. A remarkable population of small- and medium-sized DARPP-32-ir cells was found mainly in the internal granular layer of the olfactory bulbs (Fig. 2a). This population was intermingled with the group of dopaminergic (THir) cells present in the internal granular layer of this re- gion, but colocalization was not observed (Fig. 6d). In addition, a scarce group of scattered DARPP-32-ir cells was detected also on the mitral cell layer (Fig. 2a).

The most intense immunoreactivity was found in subpallial telencephalic structures. This staining was especially prominent along the rostrocaudal extent of the striatum (Fig. 2b-d, 3a-c, 6a, 8a). The intense DARPP32 -ir striatal cells appeared packaged in the external area of the periventricular layer of the dorsal and ventral striatum (Fig. 3b). These pear-shaped cells showed long processes laterally directed to the external striatal fiber zone (Fig. $2 b-d, 3 a-c, 6 e$ ), which received a dense catecholaminergic innervation and terminal-like structures 


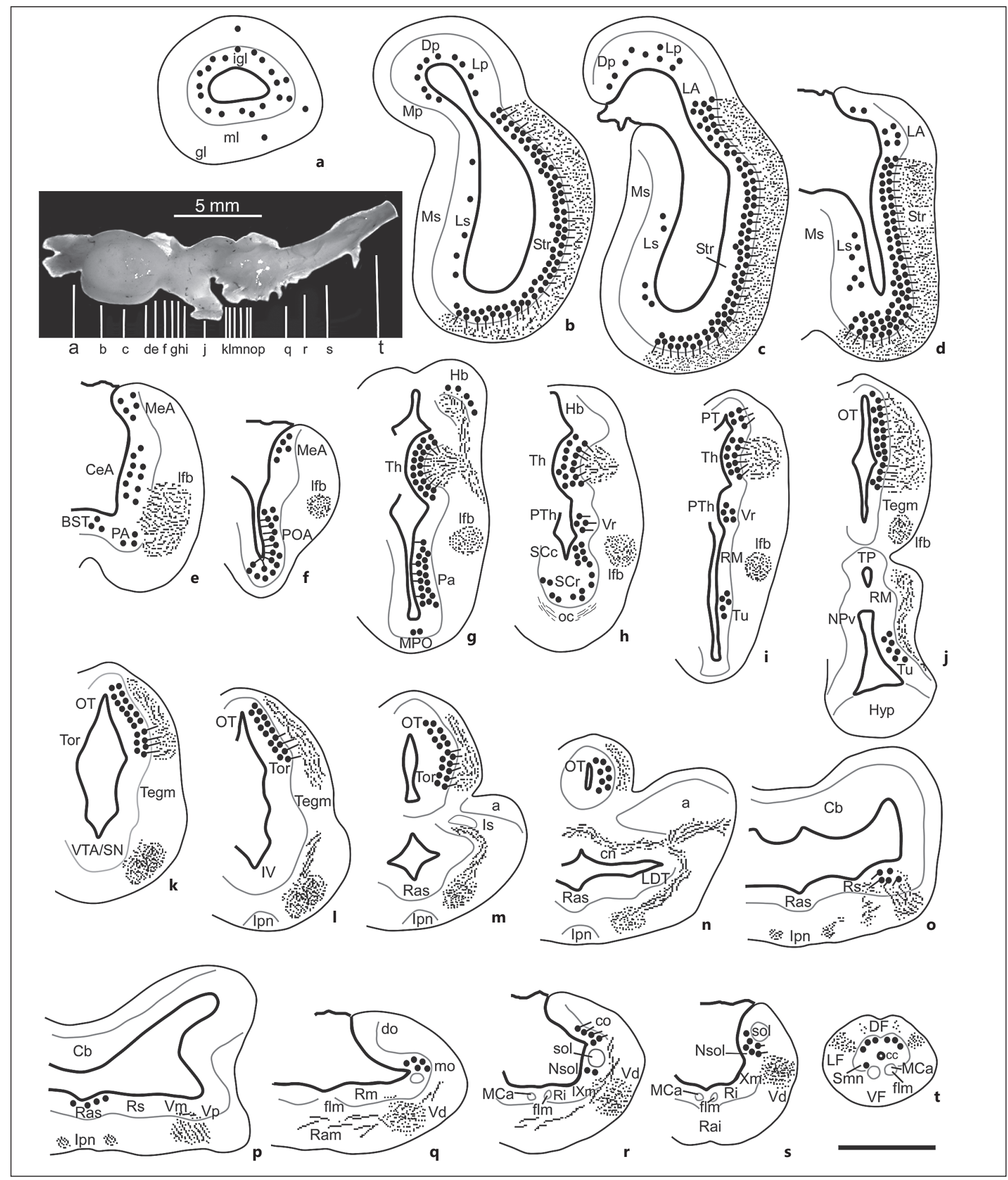

Fig. 2. a-t Diagrams of transverse sections through the brain of the lungfish $N$. forsteri at the levels indicated in the photograph of the lateral view of the brain. DARPP-32-ir cell bodies (large dots) and fibers (small dots, wavy lines) are represented in the right half of each section. See list of abbreviations. Scale bar, $500 \mu \mathrm{m}$. 


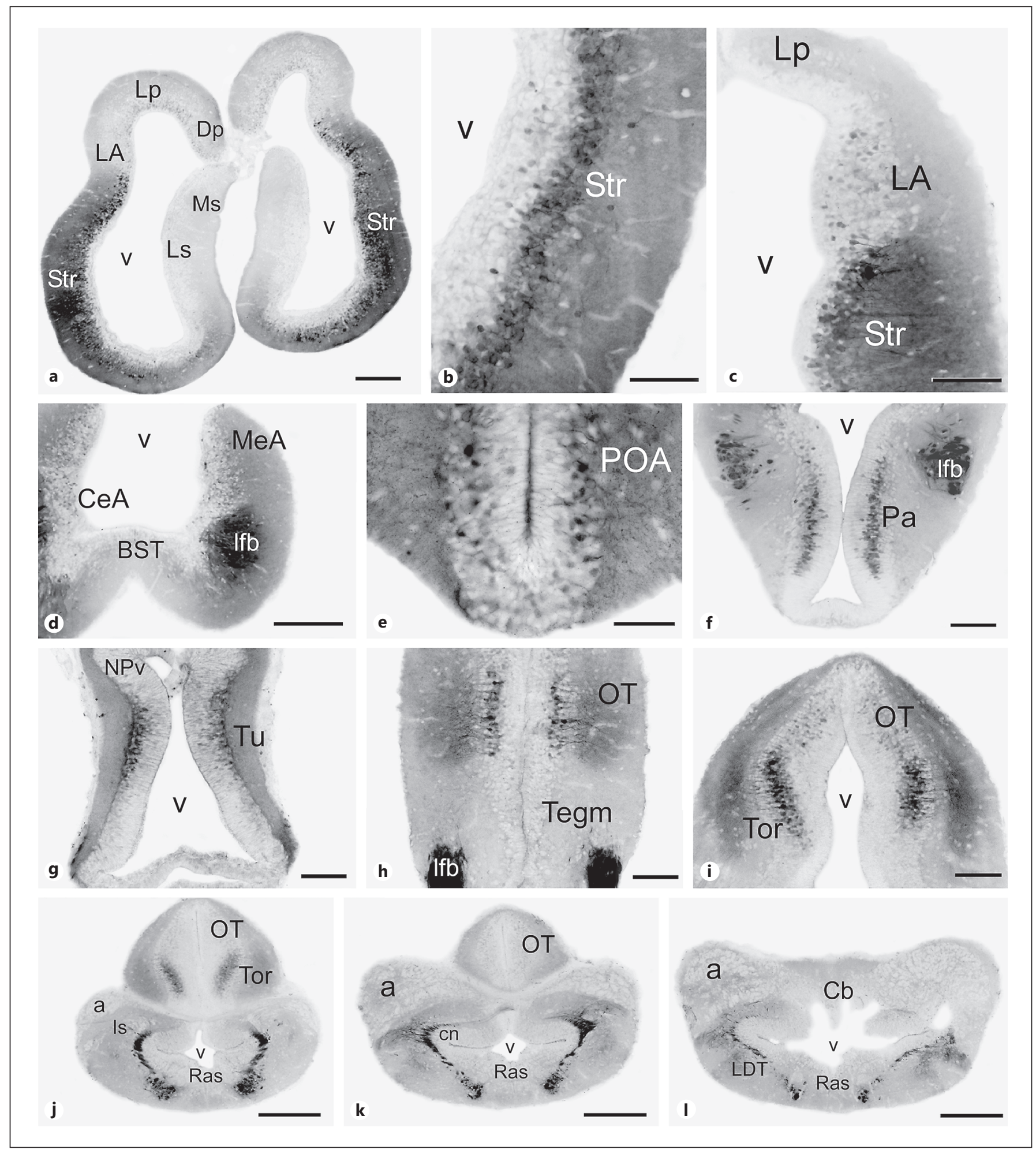

Fig. 3. Photomicrographs of transverse sections through the brain of $N$. forsteri illustrating DARPP-32-ir cell bodies and fibers in the pallial and subpallial areas (a), rostral striatum (b), caudal striatum and lateral amygdala (c), central and medial amygdala (d), preoptic area (e), paraventricular region and lateral forebrain bundle (f), tuberal hypothalamus $(\mathbf{g})$, rostral and caudal optic tectum and torus semicircularis $(\mathbf{h}, \mathbf{i})$, and rostral rhombencephalon $(\mathbf{j}-\mathbf{I})$. See list of abbreviations. Scale bars, $100 \mu \mathrm{m}(\mathbf{e}), 200 \mu \mathrm{m}$ (b, c, f-i), $500 \mu \mathrm{m}$ (a, d, j-I). 


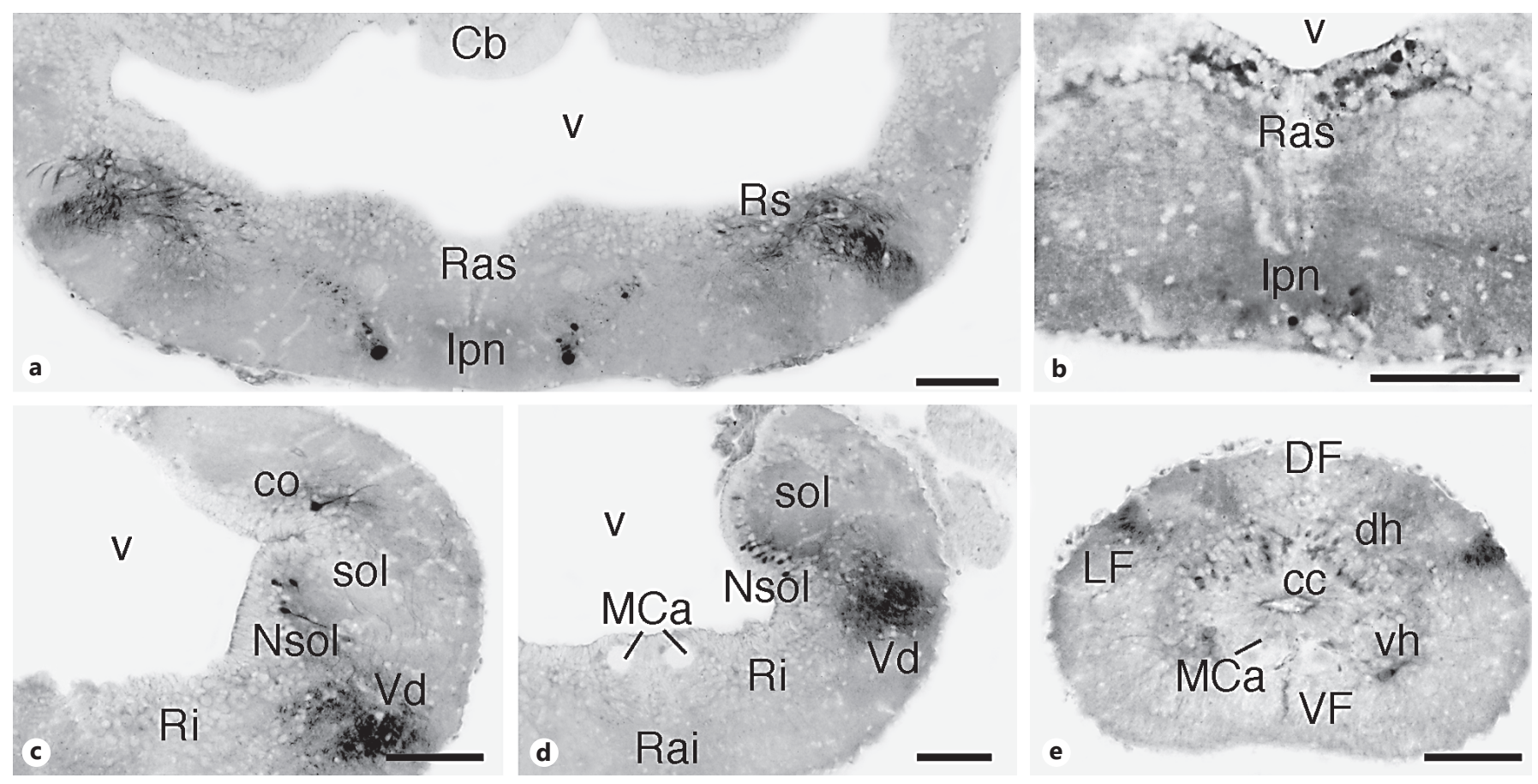

Fig. 4. Photomicrographs of transverse sections through the brainstem of $N$. forsteri illustrating DARPP-32-ir cell bodies and fibers in the pretrigeminal superior reticular nucleus (a), superior raphe nucleus (b), rostral solitary tract and caudal octavolateral nuclei (c), caudal solitary tract nucleus (d), and spinal cord (e). See list of abbreviations. Scale bars, $200 \mu \mathrm{m}$.

(Fig. 6b, c). Only in Protopterus, the striatal region possesses islands of cells migrated from the periventricular cell layer that extend into the ventrocaudal telencephalic lobe. The double labeling for DARPP-32 and TH showed the strongly DARPP-32-ir cells (Fig. 5a, b) and they were surrounded by TH-ir terminal-like structures (Fig. 8d-f, j). Of note, not all the striatal groups of cells were DARPP32-ir (Fig. 8j). Fiber bundles that originated in the striatal DARPP-32-ir cells coursed caudally and joined the lateral forebrain bundle towards the diencephalon and brainstem (Fig. 2e-k, 3d, f, h, 5d, 6f, 7a, g). A scarce group of DARPP-32-ir cells was also observed on the septal region, mainly located in the periventricular part of the lateral septum (Fig. 2b-d, 6a).

At mid-caudal levels of the telencephalon, a remarkable population of DARPP-32-ir cells was observed in the amygdaloid complex (Fig. 2d-f). They were located close to the ventricle and showed a lateral or ventrolateral cell process, primarily in the central amygdala, which constitutes the caudal continuation of the striatal region (Fig. 2e, 3d). DARPP-32-ir cells were only scarce in the lateral and medial amygdala (Fig. 2d-f, 3c, 5c, 6a). The combination of the TH and DARPP-32 staining highlighted the striato-amygdaloid boundary through the low staining of the lateral amygdala in contrast to the intense labelling shown in the striatal cells (DARPP-32) and neuropil (TH), which was more patent in Protopterus (Fig. 8a-c) than in Neoceratodus (Fig. 6a-c, e). Some DARPP-32-ir cells were located in the bed nucleus of the stria terminalis and the pallidal region (Fig. 2e, 3d, 5d), in close relation with intensely TH-ir fibers and terminals (Fig. 8g-i).

The preoptic area contained a numerous population of DARPP-32-ir cells around the rostral preoptic recess of the third ventricle. They generally showed 2 processes, 1 short contacting with the cerebrospinal fluid (CSF), and a second process laterally or ventrolaterally directed (Fig. 2f, 3e). Catecholaminergic cells were intermingled with DARPP-32-ir in this area but the actual colocalization of both markers in the same neurons was not observed (Fig. 6f). Caudally, some labeled cells were found in the median preoptic nucleus (Fig. $2 \mathrm{~g}$ ) within the most ventral part of the preoptic region.

Within the current prosomeric model that we have followed, the hypothalamus is considered to be located 
topologically ventral to the telencephalon and rostral to the diencephalon, although due to the sharp flexure of the brain axis it appears under the diencephalon in classical transverse sections [Puelles and Rubenstein, 2003, 2015]. As in the caudal parts of the brain, dorsal alar regions and ventral basal regions constitute the hypothalamus. The alar hypothalamic regions are continuous with alar regions of the diencephalon and consist of the paraventricular and subparaventricular regions. In the basal part of the hypothalamus, the tuberal region is dorsorostral to the ventrocaudal mamillary region [López et al., 2017].

In the dorsal part of the alar hypothalamus, a population of DARPP-32-ir cells occupied the paraventricular region. These cells formed a band parallel to the ventricle and possessed long and thin processes that in some cases contact the CSF (Fig. 2g, 3f). A prominent innervation of catecholaminergic fibers and terminal like-structures was observed in this area. In the ventral part of the alar hypothalamus or subparaventricular region, the rostral and caudal parts of the suprachiasmatic nucleus showed a remarkable group of DARPP-32-ir neurons that did not show CSF-contacting processes (Fig. 2h, 7a). This population was intermingled with the numerous groups of catecholaminergic cells of this region (Fig. 7b). In general, double-labeled cells were not observed, with the only exception of the rostral part of the suprachiasmatic nucleus of Neoceratodus (Fig. 7c). The small optic chiasm of lungfishes presented some immunoreactive fibers (Fig. 2h). Within the basal hypothalamus, the tuberal region contained DARPP-32-ir cells (Fig. 2i, j, 3g) that were generally migrated from the ventricle and showed long CSFcontacting processes. In the caudal tip of the infundibulum, DARPP-32-ir fibers were seen in the median
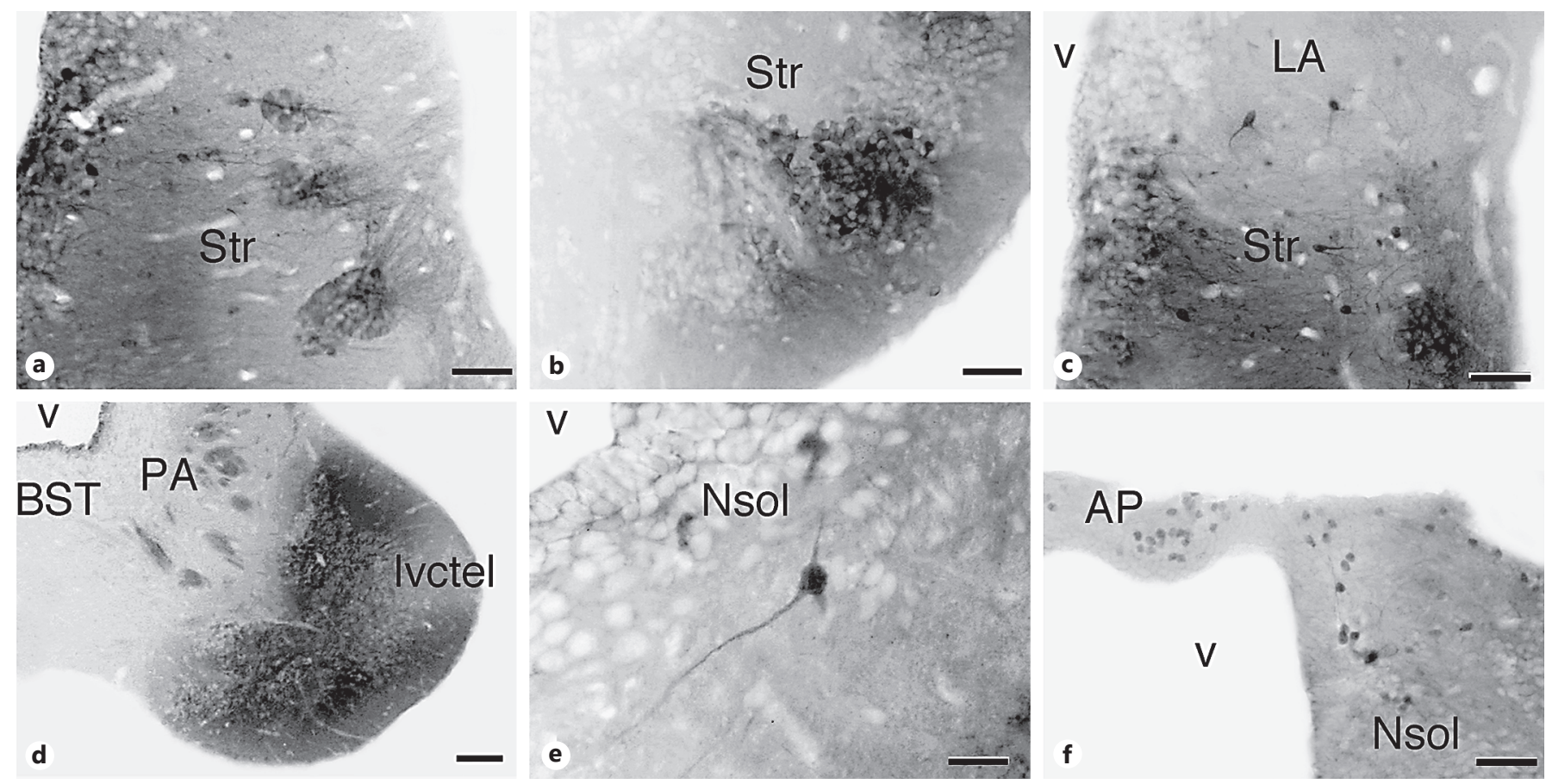

Fig. 5. Photomicrographs of transverse sections through the brain of $P$. dolloi illustrating DARPP-32-ir cell bodies and fibers in the striatum including the migrated cell islands of the caudoventral striatum $(\mathbf{a}, \mathbf{b})$, caudodorsal striatum boundary with the lateral amygdala (c), caudal tip of the telencephalic hemisphere at the lev- el of the lobus ventrocaudalis telencephali (d), rostral part of the solitary tract nucleus (e), and caudal part of the solitary tract nucleus and the region of the area postrema (f). See list of abbreviations. Scale bars, $50 \mu \mathrm{m}(\mathbf{e}), 100 \mu \mathrm{m}(\mathbf{a}-\mathbf{c}, \mathbf{f}), 200 \mu \mathrm{m}(\mathbf{d})$.
Fig. 6. Photomicrographs of double-labeled transverse sections showing staining for DARPP-32 (green fluorescence) and TH (red fluorescence) in $N$. forsteri. The relationship between the distinct immunoreactive elements is illustrated for striatal and septal re- gions (a-c), olfactory bulb (d), dorsal striatum and lateral pallium (e), the preoptic area (f), and the thalamus $(\mathbf{g}-\mathbf{i})$. See list of abbreviations. Scale bars, $100 \mu \mathrm{m}(\mathbf{d}-\mathbf{f}), 200 \mu \mathrm{m}(\mathbf{g}-\mathbf{i}), 500 \mu \mathrm{m}(\mathbf{a}-\mathbf{c})$.

(For figure see next page.) 

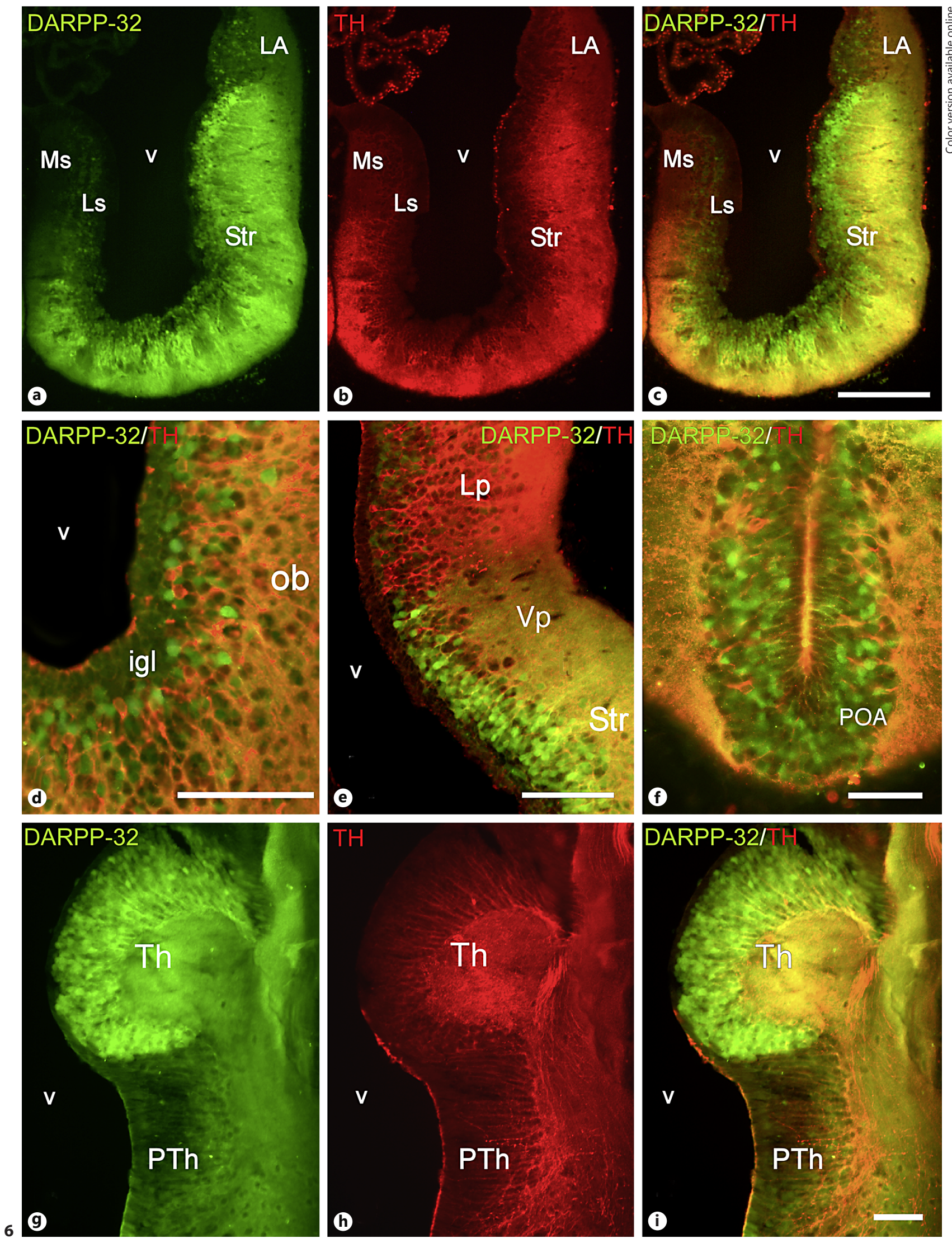

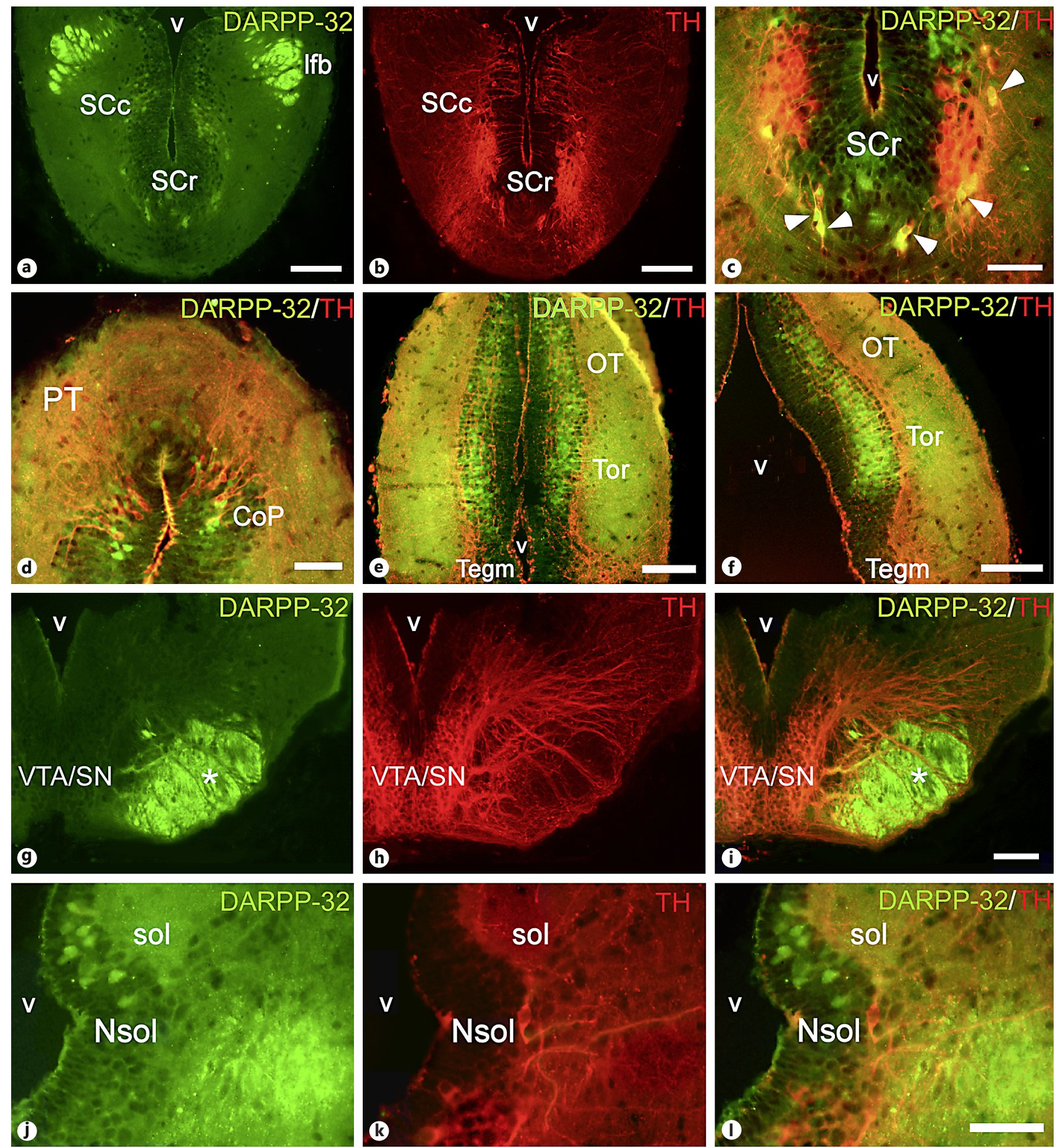

Fig. 7. Photomicrographs of double-labeled transverse sections showing staining for DARPP-32 (green fluorescence) and TH (red fluorescence) in $N$. forsteri. The relationship between the distinct immunoreactive elements is illustrated for the suprachiasmatic nucleus (a-c; arrowheads point to double-labeled cells), pretectum (d), optic tectum and torus semicircularis $(\mathbf{e}, \mathbf{f}), \mathrm{TH}$-ir cells of the ventral tegmental area/substantia nigra complex in the mesencephalic tegmentum (h) in relation to the descending DARPP-32-ir fibers (asterisks in $\mathbf{g}$ and $\mathbf{i}$ ), and the solitary tract nucleus $(\mathbf{j}-\mathbf{I})$. See list of abbreviations. Scale bars, $100 \mu \mathrm{m}(\mathbf{c}-\mathbf{g}, \mathbf{j}-\mathbf{I}), 200 \mu \mathrm{m}(\mathbf{a}$, b, h, i). 
eminence and no labeled cells were seen in the hypophysis.

In the diencephalon, from rostral to caudal, distinct DARPP-32-ir cell populations occupied the prethalamus (formerly ventral thalamus), the thalamus (formerly dorsal thalamus), and pretectum (Fig. $2 \mathrm{~g}-\mathrm{i}$ ). By far the most numerous group of immunoreactive cells was observed in the thalamus of Neoceratodus (Fig. $2 \mathrm{~g}-\mathrm{i}$ ). They were strongly packed periventriculary and with processes directed to the lateral neuropil, which contained abundant catecholaminergic fibers (Fig. $6 \mathrm{~g}-\mathrm{i}$ ). In contrast, the thalamic labeling in Protopterus was less conspicuous and virtually no immunoreactive cells were detected. In the epithalamus, scarce and scattered labeled DARPP-32-ir cells were observed in the habenula (Fig. 2g), whereas in the prethalamus a small group of DARPP-32-ir cells were seen exclusively in the rostral part of the ventral thalamic nucleus of Neoceratodus (Fig. 2h, i), but not in Protopterus. The pretectal region housed another small DARPP32 -ir cell population within the commissural pretectal nucleus formed by pear-shaped cells whose processes were directed laterally or dorsolaterally (Fig. 2i). In this pretectal region a prominent catecholaminergic group was also observed only in Neoceratodus [López et al., 2017; López and González, 2017], but these cells were more dorsally located (Fig. 7d) and no actual colocalization of both proteins was detected in the same neurons.

\section{Brainstem}

In the dorsal part of the midbrain, the optic tectum contained conspicuous DARPP-32-ir cells and fibers throughout its rostrocaudal extent. Numerous DARPP32-ir neurons were densely packed in the periventricular zone (Fig. $2 \mathrm{j}-\mathrm{n}, 3 \mathrm{~h}, \mathrm{i}$ ), also called stratum griseum periventriculare [Northcutt, 1980], which showed long cell processes directed laterally (Fig. $3 \mathrm{~h}, \mathrm{i}$ ). This cell population received a strong catecholaminergic innervation (Fig. 7e, f), mainly distributed in the stratum griseum centrale, although terminal-like structures were also labeled intermingled with the DARPP-32-ir cells in the periventricular layer (Fig. 7e, f). DARPP-32-ir fibers formed by the dendritic arborizations of the immunoreactive cells were also profuse in the intermediate zone (Fig. $2 \mathrm{j}-1,3 \mathrm{~h}$, i). Beneath the optic tectum, a group of labeled cells occupied the small torus semicircularis. These cells contained long processes that branched profusely in the superficial fiber zone (Fig. 2k-m, 3i). This brain region also presented an intense catecholaminergic innervation (Fig. 7e, f). As previously noted, DARPP-32-ir fibers originating in the striatum coursed towards the lateral fore- brain bundle and reached the mesencephalic tegmentum (Fig. $2 \mathrm{k}, 3 \mathrm{~h}, 7 \mathrm{~g}$ ), in a region heavily populated with dendrites of the dopaminergic cells of the ventral tegmental area/substantia nigra complex, which formed a densely packed cell group located close to the midline (Fig. 7g-I, 81).

Caudal to the midbrain tegmentum, the labeled fibers continued and some of them turned dorsally towards the cerebellar nucleus and the cerebellar auricle (Fig. 2l-n, $3 j-1)$. Some of these fibers crossed to the other side in the cerebellar commissure (Fig. 2n). More caudally, some of these labeled fibers reached the principal trigeminal sensory nucleus (Fig. 2p, 4a). In the superior reticular nucleus, some DARPP-32-ir neurons with long processes ventromedially directed were located rostral to the trigeminal motor nucleus (Fig. 2o, 4a). The remaining immunoreactive fibers were observed in the ventromedial fiber zone of the hindbrain, lateral to the interpeduncular neuropil (Fig. 2o, p, 4a).

Both the isthmic and the interpeduncular nuclei were almost devoid of immunoreactive cells/fibers (Fig. 2m-o). The corpus cerebelli also lacked DARPP-32-ir elements (Fig. 2o, p, 3l), whereas near the midline some rounded DARPP-32-ir cells were seen in the superior raphe nucleus (Fig. 2p, 4b). A rich plexus of labeled fibers and terminal-like structures were observed ventrolaterally within the descending trigeminal nucleus (Fig. 2q-s, 4c, d).

With the exception of the pretrigeminal reticular group mentioned above, the rhombencephalic reticular formation was devoid of DARPP-32-ir cells throughout its rostrocaudal extent, whereas, in the alar plate of the rhombencephalon, a group of DARPP-32-ir neurons was observed in the medial and caudal nuclei of the octavolateral area of Neoceratodus (Fig. 2q, r, 4c). These piriform cells possessed long processes laterally directed that crossed the midline to the contralateral side of the rhombencephalon (Fig. 2q, r, 4c). In Protopterus, these immunoreactive cells were seen only in the caudal octavolateral nucleus.

In the caudal rhombencephalon and around the solitary tract a remarkable group of DARPP-32-ir cells was observed in the solitary tract nucleus (Fig. 2r, s, 4d, 5e). In experiments of double immunolabeling, some of these cells, mainly located ventral to the solitary tract, showed coexpression with TH in Protopterus (Fig. 8m-o) but not in Neoceratodus (Fig. 7j-1). It is noteworthy that only in Protopterus were some small immunoreactive cells seen dorsomedially to the solitary tract within the area postrema (Fig. 5f). 

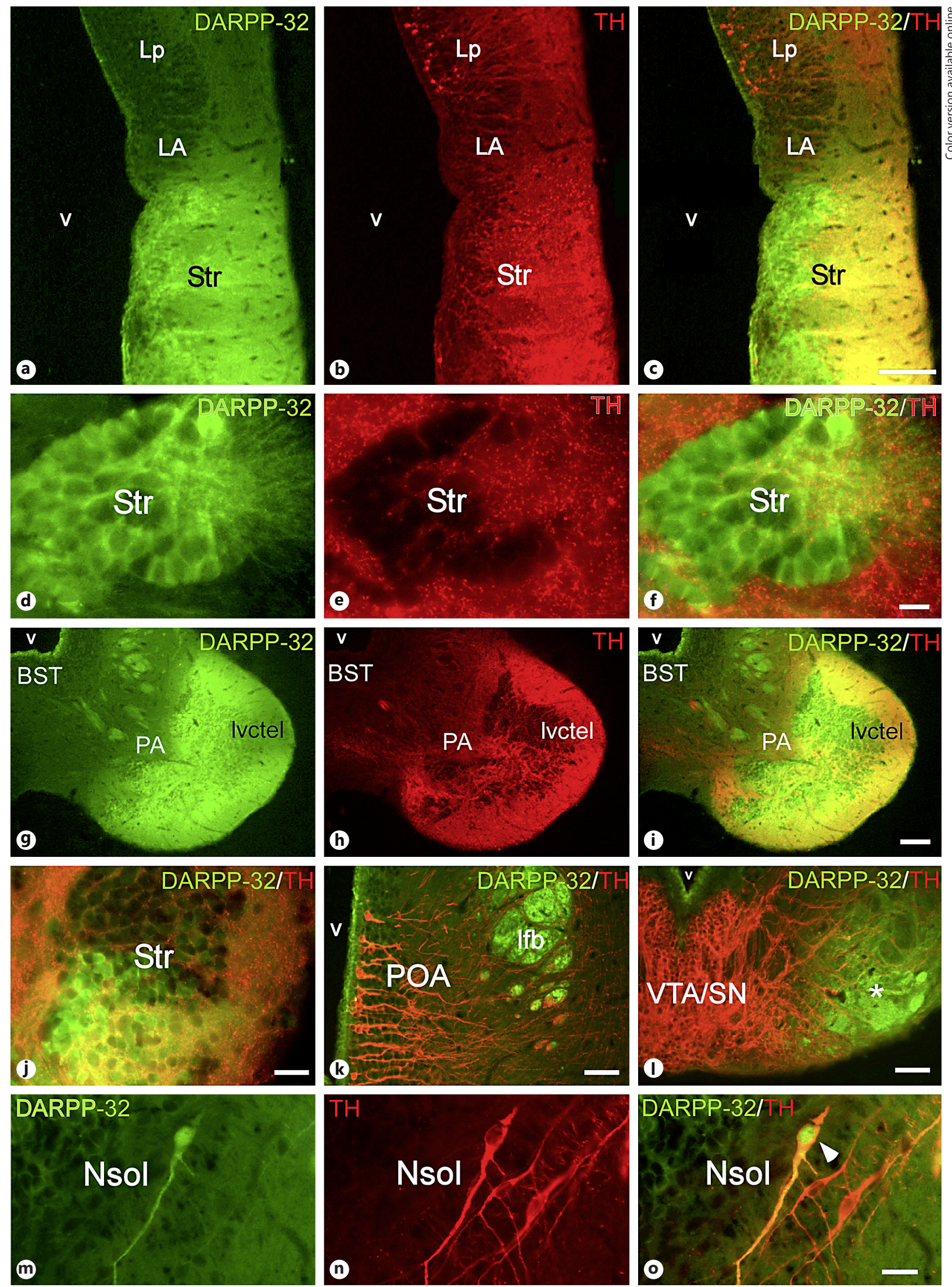

(For legend see next page.) 
Finally, a remarkable population of DARPP-32-ir cells was observed in the rostral part of the spinal cord. These small cells were situated mainly in the dorsal and lateral fields of the gray matter (Fig. 2t, 4e) and showed processes dorsolaterally directed that extended into the lateral and laterodorsal funiculi. In addition, occasional and weakly labeled cells were observed in the ventral spinal gray matter (Fig. 4e). The localization of immunoreactive cells was coincident with the catecholaminergic innervation observed in these fields of the spinal gray matter [López and González, 2017; present results]. The highest density of DARPP-32-ir fibers was observed in the dorsal and laterodorsal funiculi of the spinal white matter (Fig. 2t, 4e).

\section{Discussion}

The present study has served to evaluate the presence of a complete system of DARPP-32-containing neurons in the brain of 2 lungfish species that, in general, is fully comparable to those described for the limbed vertebrates (tetrapods). Therefore, the previously reported idea that this protein might be absent from the anamniote vertebrate classes [Hemmings and Greengard, 1986] seems to be contradicted. Moreover, our Western botting analysis and the immunohistochemical demonstration of DARPP-32 in the brain of lungfishes (the closest living relatives of tetrapods) with the same antibody used in previous studies from amphibians to mammals supports a conservation throughout sarcopterygians. In other Osteichthyes, including bony fishes, due to the lack of conservation of epitopes, the use of the antibody against bovine DARPP-32 may explain the lack of immunoreactivity. However, it should be noted that sequence comparisons

Fig. 8. Photomicrographs of double-labeled transverse sections showing staining for DARPP-32 (green fluorescence) and TH (red fluorescence) in P. dolloi. The relationship between the distinct immunoreactive elements is illustrated for dorsal striatum and the boundary with the lateral amygdala $(\mathbf{a}-\mathbf{c})$, detail of migrated striatal cell island (d-f, $\mathbf{j})$, caudal tip of the telencephalic hemisphere, at the level of the lobus ventrocaudalis telencephali $(\mathbf{g}-\mathbf{i})$, the lateral forebrain bundle and preoptic area (k), TH-ir cells of the ventral tegmental area/substantia nigra complex in the mesencephalic tegmentum in relation to the descending DARPP-32-ir fibers (asterisk in I), and the solitary tract nucleus ( $\mathbf{m}-\mathbf{o}$, arrowhead in $\mathbf{o}$ points to a double-labeled cell). See list of abbreviations. Scale bars, $20 \mu \mathrm{m}$ (d-f), $50 \mu \mathrm{m}$ (j, m-o), $100 \mu \mathrm{m}(\mathbf{k}, \mathbf{I}), 200 \mu \mathrm{m}(\mathbf{a}-\mathbf{c}, \mathbf{g}-\mathbf{i})$.

DARPP-32 in the Brain of Lungfishes show that all PPP1R1 family members are actually found in all Osteichthyes [Yger and Girault, 2011].

Our results show that, in general, according to the distribution of DARPP-32-ir cells in the brain of lungfishes, they may actually represent targets for dopaminergic fibers [López and González, 2017]. This is in line with all previous studies in amniotes showing that DARPP-32 was enriched in dopamine-innervated brain regions [Ouimet et al., 1984]. In the following section, the general organization and variations of the distribution of DARPP-32 in the brain of lungfishes are discussed and compared with those of other vertebrates (Table 1). In this regard, as mentioned in the Introduction, the results of the distribution of DARPP-32 in the brain of the zebrafish [Robra and Thirumalai, 2016] should be taken with caution since they were obtained differently from those of tetrapods, with which the comparison is more reliable.

\section{Comparative Aspects of the Regional Distribution of \\ DARPP-32}

Telencephalon

DARPP-32-ir cells are located in the mitral and internal granular layers of the olfactory bulbs in lungfishes in close relation to dopaminergic cells and fibers, as in amphibians [López et al., 2010; O'Connell et al., 2010] and reptiles [Smeets et al., 2001, 2003]. However, in reptiles DARPP-32-ir cells are more abundant within the anterior olfactory nucleus and the olfactory tubercle [Smeets et al., 2001, 2003], as is also the case in birds and mammals [Ouimet et al., 1984, 1992; Perez and Lewis, 1992; Schnabel et al., 1997]. In contrast, DARPP-32-ir cells were not reported in the zebrafish olfactory bulbs [Robra and Thirumalai, 2016].

All pallial regions of Neoceratodus possess scattered DARPP-32-ir cells, whereas in the pallium of Protopterus no cells are detected. This specific and variable feature was also described in anuran amphibians, where a notable population of DARPP-32-ir cells was observed in all pallial areas of the Physalaemus pustulosus [O'Connell et al., 2010] but not in X. laevis and Rana perezi [López et al., 2010]. Also, the pallium of zebrafish is devoid of DARPP-32-ir cells [Robra and Thirumalai, 2016]. In contrast, the cortical areas of reptiles, birds, and mammals contain DARPP-32-ir cells [Ouimet et al., 1984, 1992; Berger et al., 1990; Durstewitz et al., 1998; Absil et al., 2001; Smeets et al., 2001, 2003; Wang et al., 2004; Ishikawa et al., 2007; Csillag et al., 2008; Glausier et al., 2010], representing a constant feature shared by all amniotes studied. Particularly relevant is the presence of 
DARPP-32-ir cells in the prefrontal cortex of mammals, which receives a strong dopaminergic innervation from the ventral tegmental area, and plays a critical role in working memory and selective attention tasks [Goldman-Rakic et al., 2000].

The most conspicuous DARPP-32-ir cell population in the lungfish brain is located in the telencephalic region identified as the striatum, in relation to the intense dopaminergic innervation [González and Northcutt, 2009; González et al., 2014; López and González, 2017]. This is directly comparable to the situation found in amniotes. Actually, the first studies of the DARPP-32 distribution in mammals showed that $>85 \%$ of the medium-sized spiny neurons in the striatum contain this protein [Walaas and Greengard, 1984; Ouimet et al., 1998; Anderson and Reiner, 1991]. These cells were directly related to the GABAergic striatal projection neurons containing the $D_{1}$ receptor and are considered as the most important integrator between the cortical input and the basal ganglia, and associated with motor control [Svenningsson et al., 2004; Tepper and Bolam, 2004; Petryszyn et al., 2017]. The importance of the DARPP-32 in striatal functioning is evident in human Huntington disease and also in animal models, in which DARPP-32 is downregulated in the striatum and the effects on transcription seem an essential feature of the pathogenesis [Cha, 2007; Runne et al., 2008; Young et al., 2013]. Comparable results in the location of DARPP-32 were obtained in the avian and reptilian striatum [Schnabel et al., 1997; Durstewitz et al., 1998; Reiner et al., 1998; Smeets et al., 2001, 2003; Scott et al., 2002; Bálint et al., 2004; Csillag et al., 2008; Huang et al., 2014]. The present results add lungfishes to tetrapods in this common feature of striatal neurons, most likely indicating an underlying functional homology. In contrast, striatal-specific transcription factors in the ventral telencephalon of teleosts suggested the location of the striatum in the dorsal and central nuclei, [Wullimann and Mueller, 2004; Bally-Cuif and Vernier, 2010; Ganz et al., 2012; González et al., 2014], and although catecholaminergic innervation was abundant in this region, no DARPP-32-ir cells were detected [Robra and Thirumalai, 2016], suggesting distinct neuromodulatory mechanisms in the striatum of actinopterygian fishes, although more studies are needed in other species and with different technical approaches.

Also in the telencephalon, DARPP-32-ir cells are present in the lateral septum, the bed nucleus of the stria terminalis, and the amygdaloid complex of the 2 lungfishes studied, with the exception of the lateral amygdala of Protopterus that lacks immunoreactive cells. This situation is similar to that observed in the septal region and the amygdaloid complex of anuran amphibians [López et al., 2010; O’Connell et al., 2010] and shared with all amniotes studied [Ouimet et al., 1984, 1992; Schnabel et al., 1997; Durstewitz et al., 1998; Absil et al., 2001; Smeets et al., 2001, 2003; Roberts et al., 2002]. In contrast, the suggested homolog areas of the septum and amygdaloid complex in the ventral telencephalon of zebrafish [Ganz et al., 2012; González et al., 2014] are devoid of DARPP-32 immunoreactivity [Robra and Thirumalai, 2016].

Finally, DARPP-32-ir cells are located within the preoptic area of lungfishes. The preoptic area has classically been considered the rostral-most part of the hypothalamus, but is currently considered a nonevaginated telencephalic region [Moreno and González, 2011; Domínguez et al., 2013, 2015]. The presence of DARPP-32-ir preoptic cells is a feature conserved in most species of vertebrates studied, with the exceptions of the turtle and zebrafish [Smeets et al., 2003; Robra and Thirumalai, 2016]. In rats, DARPP-32 has been related to the modulation of sexual behavior in the medial preoptic nucleus [Meredith et al., 1998; McHenry et al., 2012].

\section{Hypothalamus}

Within the alar hypothalamus of lungfishes, the paraventricular region and the suprachiasmatic nucleus in the subparaventricular region contain some populations of DARPP-32-ir cells. These populations have been described in similar locations of the amphibian alar hypothalamus [López et al., 2010; O'Connell et al., 2010] but not in amniotes [Ouimet et al., 1984, 1992; Absil et al., 2001; Smeets et al., 2001, 2003; Yan et al., 2006] or the teleost zebrafish [Robra and Thirumalai, 2016]. In contrast, the presence of DARPP-32-ir cells in the tuberal hypothalamus is a conserved feature described in all groups of vertebrates studied (Table 1), although its distribution was quite reduced in mammals [Ouimet et al., 1984; Hemmings et al., 1992]. The upregulation of DARPP-32 as well as other dopamine-related gene products in the orexinergic neurons of the lateral hypothalamus of rats by sodium deficiency has been reported, suggesting an ancient connection between the hypothalamic mechanism of salt appetite and the hedonic liking of salt taste [Liedtke et al., 2011]. Interestingly, we have previously described the presence of orexinergic cells in the tuberal hypothalamus of lungfishes [López et al., 2009], and similar interactions could take place. 


\section{Diencephalon}

The diencephalon of Neoceratodus contains a prominent group of DARPP-32-ir cells in the thalamus, and a small cell group is located in the prethalamus. In contrast, virtually no immunoreactive cells were detected in the thalamus and prethalamus of Protopterus. This variable distribution has also been described within the diencephalon of anuran amphibians, where DARPP-32-ir cells were reported in the thalamus of $R$. perezi and P. pustulosus but not in X. laevis [López et al., 2010; O'Connell et al., 2010], whereas DARPP-32-ir cells were seen in the prethalamus of Xenopus and Physalaemus but not in Rana [López et al., 2010; O'Connell et al., 2010]. DARPP32 -ir cells were not observed in the prethalamus of amniotes and zebrafish. However, DARPP-32-ir neurons are located in the medial and posterior thalamic nuclei of Gekko and only in the medial thalamic nucleus of the Pseudemys turtle [Smeets et al., 2001, 2003]. In birds, DARPP-32-ir cells were seen in the nucleus rotundus and in some parts of anterior and posterior thalamic nuclei [Absil et al., 2001], whereas no immunoreactive cells have been detected in mammals and zebrafish. Thus, the presence of DARPP-32-ir cells in the thalamus seems to be a primitive and variable sarcopterygian feature lost in mammals.

The presence of DARPP-32-ir cells in the habenula is a feature shared by all species of sarcopterygian vertebrates studied [Ouimet et al., 1984, 1992; Perez and Lewis, 1992; Schnabel et al., 1997; Durstewitz et al., 1998; Absil et al., 2001; Smeets et al., 2001, 2003; Roberts et al., 2002; López et al., 2010; O'Connell et al., 2010; present results], whereas they are absent in zebrafish [Robra and Thirumalai, 2016]. In lungfishes and birds, these immunoreactive cells are located in the lateral habenular region [Absil et al., 2001; present results], whereas in amphibians, reptiles, and mammals these cells are confined in the medial habenular subdivision [Ouimet et al., 1984, 1992; Perez and Lewis, 1992; Smeets et al., 2001, 2003; López et al., 2010]. Symmetrical DARPP-32 immunoreactivity is found in the habenula of lungfishes, as it has been also described in other species of tetrapods, with the unique exception of the anuran amphibian $R$. perezi, which possess DARPP-32-ir cells only in the left habenula [López et al., 2010].

The pretectal region of lungfishes houses a small DARPP-32-ir cell population within the commissural nucleus identified in anurans [Morona et al., 2011, 2017]. Also, in the pretectum of anuran amphibians a small number of DARPP-32-ir cells were observed in the commissural and juxtacommissural pretectal nuclei [López et al., 2010], whereas amniotes and zebrafish lack DARPP32 -ir pretectal cells. This fact seems to be a primitive feature present in anamniote sarcopterygians.

\section{Mesencephalon}

The mesencephalic optic tectum of lungfishes houses a large population of DARPP-32-ir cells in the periventricular zone throughout its rostrocaudal extent, in close relation to a notable catecholaminergic innervation [López and González, 2017; present results]. Likewise, DARPP-32-ir cells occupy deep layers of the optic tectum of zebrafish and the anuran amphibians studied, also receiving a strong catecholaminergic innervation [González and Smeets, 1991, 1994; González et al., 1993; SánchezCamacho et al., 2002; López et al., 2010; O’Connell et al., 2010; Robra and Thirumalai, 2016]. In amniotes, a remarkable population of DARPP-32-ir cells was also observed in the deep tectal layers of reptiles [Smeets et al., 2001, 2003], but in superficial tectal layers of birds [Araki et al., 2000; Absil et al., 2001; Metzger et al., 2006]. These different localizations reflected the distribution of $\mathrm{TH}$-ir fibers, located in more superficial tectal layers in birds [Metzger et al., 2006]. In sharp contrast, no DARPP-32-ir cells have been detected in the superior colliculus of mammals [Ouimet et al., 1984, 1992; Walaas and Greengard, 1984]. Thus, the presence of tectal DARPP-32-ir cells seems to be a primitive feature of the brain of vertebrates that has been lost in mammals.

DARPP-32-ir cells also occur in the small torus semicircularis of lungfishes, which also contains an intense catecholaminergic innervation [López and González, 2017; present results]. A largely similar situation was found in the torus semicircularis of anuran amphibians [López et al., 2010; O'Connell et al., 2010] and reptiles [Smeets et al., 2001, 2003]. In birds, some immunoreactive cells have been detected in the nucleus intercollicularis [Absil et al., 2001], whereas no immunoreactive cells have been described in the torus semicircularis of zebrafish [Robra and Thirumalai, 2016] and the inferior colliculus of mammals [Ouimet et al., 1984, 1992; Walaas and Greengard, 1984]. Thus, the presence of toral DARPP32 -ir cells seems to be a primitive sarcopterygian character absent in mammals.

The mesencephalic tegmentum of the lungfishes studied is devoid of DARPP-32-ir cells. Only in anurans have DARPP-32-ir cells been reported in the midbrain tegmentum [López et al., 2010; O'Connell et al., 2010], which seems to be a peculiar feature present only in amphibians. However, immunoreactive fibers in the ventral tegmental area and the pars reticulata of the substantia nigra arising 
in the striatal DARPP-32-ir cells have been consistently observed in all tetrapods [Ouimet et al., 1984, 1992; Walaas and Greengard, 1984; Absil et al., 2001; Smeets et al., 2001, 2003; Bálint et al., 2004]. Interestingly in lungfishes, intense DARPP-32-ir fibers and terminals are located lateral to the prominent $\mathrm{TH}$-ir cell group readily comparable to the VTA/SN complex of tetrapods [Reiner and Northcutt, 1987; López and González, 2017]. Therefore, the characteristic presence in tetrapods of a striatonigral (striatomesencephalic) system and its reciprocal nigrostriatal (mesencephalostriatal) system [Marín et al., 1998] is a shared feature of the basal ganglia organization also in lungfishes [Marín et al., 1998; López and González, 2017]. Although detailed hodological data are needed, the presence of GABA-, SP-, and DARPP-32 fibers originating in the striatum and coursing in the lateral forebrain bundle to reach the mesencephalic tegmental region heavily populated with dendrites of TH (dopaminergic) cells, the axons of which form the bulk of the TH innervation of the striatum [López and González, 2017; López et al., 2017], support the comparison.

\section{Rhombencephalon and Upper Spinal Cord}

The isthmic nucleus in the rostral rhombencephalon, discerned in lungfishes by its cholinergic nature and tectal projections [López et al., 2012], is devoid of DARPP32-ir cells as in zebrafish [Robra and Thirumalai, 2016] and anuran amphibians [López et al., 2010]. In reptiles, DARPP-32-ir cells were found in the parvocellular portion of the nucleus isthmi [Smeets et al., 2001, 2003], whereas no immunoreactive cells have been observed in the isthmic region of birds or its counterpart in mammals, the parabigeminal nucleus [Ouimet et al., 1984; Walaas and Greengard, 1984; Ouimet et al., 1992; Absil et al., 2001].

On top of the rostral rhombencephalon, the cerebellum of lungfishes lacks DARPP-32-ir cells and fibers, whereas in amphibians some immunoreactive cells were seen in the molecular layer of $R$. perezi and P. pustulosus, but not in X. laevis, and Purkinje cells were never immunoreactive [López et al., 2010; O'Connell et al., 2010]. No DARPP-32-ir cells have been detected in the cerebellum of reptiles and birds [Absil et al., 2001; Smeets et al., 2001, 2003], whereas in zebrafish [Robra and Thirumalai, 2016] and some mammals [rodents: Ouimet et al., 1984; Perez and Lewis, 1992; primates: Ouimet et al., 1992] DARPP32-ir Purkinje cells have been reported. Therefore, this is another variable feature that has appeared several times during evolution.
Some DARPP-32-ir cells are located in the superior reticular and the superior raphe nuclei of the lungfishes studied. Much more prominent is the immunoreactive population found in the rhombencephalic reticular nuclei and raphe column of anuran amphibians [López et al., 2010; O'Connell et al., 2010]. In reptiles, no immunoreactive cells have been detected in the rhombencephalic reticular formation [Smeets et al., 2001, 2003], and only in Gekko have DARPP-32-ir cells been seen in the superior and inferior raphe nuclei [Smeets et al., 2001]. However, in birds, scattered DARPP-32-ir neurons were detected medially to the locus coeruleus and in the lateral part of the reticular formation [Absil et al., 2001], whereas no immunoreactive cells have been described in the reticular formation of mammals [Ouimet et al., 1984, 1992; Walaas and Greengard, 1984]. Therefore, the presence of DARPP-32-ir cells in the reticular and raphe nuclei is another variable species-specific feature.

In the rhombencephalic alar plate, some DARPP-32-ir neurons are located in the medial and caudal nuclei of the octavolateral area of Neoceratodus and only in the caudal octavolateral nucleus of Protopterus. Among the anamniotes studied, a remarkable population of DARPP-32-ir cells was seen in the medial octavolateral nucleus of zebrafish [Robra and Thirumalai, 2016], and in the octavolateral area of Rana, but not in Xenopus [López et al., 2010]. No immunoreactive cells were detected in similar locations of reptiles, birds, and mammals [Ouimet et al., 1984, 1992; Walaas and Greengard, 1984; Absil et al., 2001; Smeets et al., 2001, 2003] and, therefore, the presence of immunoreactive cells in this area appears to be a primitive feature present only in some species of anamniotes, primarily related to the lateral line system.

In the caudal rhombencephalon a remarkable group of DARPP-32-ir cells is localized in the solitary tract nucleus of the lungfishes studied, and extends into the area postrema only in Protopterus. Similarly, a notable population of immunoreactive cells was detected in the solitary tract nucleus of amphibians [López et al., 2010]. In reptiles, some immunoreactive cells were described in comparable regions only in Gekko, within the caudal rhombencephalic ventrolateral tegmentum and dorsal to the solitary tract [Smeets et al., 2001, 2003]. No DARPP-32-ir cells have been observed in similar rhombencephalic regions of zebrafish, birds, and mammals [Ouimet et al., 1984, 1992; Walaas and Greengard, 1984; Absil et al., 2001; Robra and Thirumalai, 2016]. Thus, the presence of immunoreactive cells around the solitary tract in the caudal rhombencephalon seems to be a primitive feature present in basal sarcopterygians and some reptiles. 
In the upper segments of the spinal cord analyzed in lungfishes, a population of DARPP-32-ir cells was observed mainly in the dorsal and lateral fields of the spinal gray matter, coinciding with the dense catecholaminergic innervation observed in these spinal areas [López and González, 2017; present results]. In the spinal cord of amphibians, a remarkable population of DARPP-32-ir cells was observed in the central, lateral, and ventrolateral fields of the gray matter, also coincident with the intense catecholaminergic innervation observed in these fields [López et al., 2010]. In the lizard Gekko gecko, DARPP32 -ir cells were seen in the dorsolateral and lateral aspect of the ventral horn, and only weakly labeled cells were present in the dorsal horn [Smeets et al., 2001], whereas no immunoreactive cells have been reported in the spinal cord of the zebrafish, turtle, birds, and mammals studied [Ouimet et al., 1984, 1992; Walaas and Greengard, 1984; Absil et al., 2001; Smeets et al., 2003]. Of note, in the rat spinal cord phosphorylated DARPP-32 has been detected in the dorsal horn of lumbar spinal levels regulating nociceptive plasticity [Buesa et al., 2016].

Codistribution/Colocalization of DARPP-32 and TH

Although confocal microscopy was not used in the present study, the double immunolabeling experiments showed close relationships between DARPP-32 and catecholaminergic neuronal structures in lungfishes, as in tetrapods [Ouimet et al., 1984, 1992; Schnabel et al., 1997; Durstewitz et al., 1998; Reiner et al., 1998; Absil et al., 2001; Smeets et al., 2001, 2003; López et al., 2010]. Also, in zebrafish, DARPP-32 cells are distributed in areas receiving dopaminergic innervation, although in this case they are primarily restricted to the cerebellum and cerebellum-like circuits [Robra and Thirumalai, 2016]. The staining pattern in lungfishes and tetrapods supports the conclusion that the DARPP-32 is present in dopaminoceptive neurons, i.e., neurons that receive a dopamine input, and that it is absent from the dopaminergic neurons themselves. However, actual colocalization of DARPP-32 and TH occurs in some cells of the suprachiasmatic nucleus of Neoceratodus and in the solitary tract nucleus of Protopterus. In amphibians, colocalization was detected in the nucleus of the solitary tract of Rana and in the ventral mesencephalic tegmentum of Xenopus [López et al., 2010], whereas in reptiles, double-labeled cells were observed in the ventral part of the periventricular hypothalamic nucleus and in the caudal rhombencephalic tegmentum exclusively in Gekko [Smeets et al., 2001, 2003]. Although a similar experimental approach has not been conducted in birds and mammals, the coexpression of both proteins in the same cells seems to be a restricted feature, with the precise location of this colocalization being a species-specific variable feature.

Some mismatches between the 2 immunoreactivities were observed in the brain of lungfishes, primarily in the rostral lateral septum and the medial amygdala (with DARPP-32-ir cells and almost devoid of TH innervation) or the cerebellum and the median and caudal reticular formation (with TH-ir innervation and devoid of DARPP-32-ir cells). These mismatches have also been reported in the dorsal and central nuclei of ventral telencephalon of zebrafish [Robra and Thirumalai, 2016], in the lateroventral septum, cerebellum and reticular formation of amphibians [López et al., 2010], the septal region, the superficial part of the medial cortex, pretectum and rhombencephalic ventromedial tegmentum of reptiles [Smeets et al., 2001, 2003], and in the neocortex and cerebellum of mammals [Ouimet et al., 1984, 1992]. These data support that DARPP-32 may not only be regulated by dopamine, but also by glutamate, serotonin, noradrenalin, nitric oxide, or somatostatin [Greengard et al., 1998; Svenningsson et al., 2002; Andersson et al., 2005; Nishi et al., 2005; Hara et al., 2010; Rajput et al., 2012; Yuste et al., 2012].

\section{Concluding Remarks}

The results of the present study show a wide distribution of DARPP-32-ir elements in all main brain regions of lungfishes, largely resembling the pattern described in tetrapods and especially in amphibians. Thus, lungfishes exclusively share with amphibians some particular features, such as the presence of DARPP-32-ir cells in the paraventricular hypothalamic area, suprachiasmatic nucleus, pretectum, and in the rhombencephalic octavolateral area. The presence of DARPP-32-ir cells in the midbrain tectum and the torus semicircularis, as well as the double-labeled cells in some brain areas, are features shared between lungfishes, amphibians, and reptiles. However, the presence of DARPP-32-ir cells within the septal region, the amygdaloid complex, the habenula, the tuberal hypothalamic area, and particularly in the basal ganglia are features strongly conserved in all sarcopterygians. The labeling pattern is notoriously different with respect to the zebrafish, which is the only actinopterygian species studied so far. It is worth noting the identification of well-developed striatonigral and nigrostriatal systems in lungfishes. 


\section{Acknowledgements}

The authors wish to thank Dr. H.C. Hemmings Jr. for kindly donating the DARPP-32 antibody and Dr. Glenn R. Northcutt for providing the brains of $N$. forsteri and for his continuous help and advice during the initial phases of this research. This work was supported by a Spanish MICINN grant, grant/award No. BFU2015-66041P (with European FEDER support).

\section{Disclosure Statement}

The authors declare that they have no conflicts of interest. No financial conflict of interest was identified, and the terms of the funding arrangement were reviewed and approved by the Complutense University of Madrid in accordance with its policy on objectivity in research.

\section{References}

Absil P, Foidart A, Hemmings HC Jr, Steinbusch HWM, Ball GF, Balthazart J (2001): Distribution of DARPP-32-immunoreactive structures in the quail brain: anatomical relationship with dopamine and aromatase. J Chem Neuroanat 21:23-39.

Adams JG (1981): Heavy metal intensification of DAB-based HRP reaction product. J Histochem Cytochem 29:775.

-Amemiya CT, Alföldi J, Lee AP, Fan S, Philippe H, Maccallum I, et al (2013): The African coelacanth genome provides insights into tetrapod evolution. Nature 496:311-316.

-Anderson KD, Reiner A (1991): Immunohistochemical localization of DARPP-32 in striatal projection neurons and striatal interneurons: implications for the localization of $\mathrm{D}_{1}$-like dopamine receptors on different types of striatal neurons. Brain Res 568:235-243.

-Andersson M, Usiello A, Borgkvist A, Pozzi L, Dominguez C, Fienberg AA, Svenningsson P, Fredholm BB, Borrelli E, Greengard P, Fisone G (2005): Cannabinoid action depends on phosphorylation of dopamine- and cAMPregulated phosphoprotein of $32 \mathrm{kDa}$ at the protein kinase A site in striatal projection neurons. J Neurosci 25:8432-8448.

-Araki CM, Metzger M, Britto LR (2000): Late developmental expression of DARPP-32 in the chick optic tectum. Brain Res 865:264-267.

-Bálint E, Csillag A (2007): Nucleus accumbens subregions: hodological and immunohistochemical study in the domestic chick (Gallus domesticus). Cell Tissue Res 327:221-230.

- Bálint E, Kitka T, Zachar G, Adám A, Hemmings HC Jr, Csillag A (2004): Abundance and location of DARPP-32 in striato-tegmental circuits of domestic chicks. J Chem Neuroanat 2004;28:27-36.

Bally-Cuif L, Vernier P (2010): Organization and physiology of the zebrafish nervous system. Fish Physiol 29:25-80.

- Barbas H, Gustafson EL, Greengard P (1993): Comparison of the immunocytochemical localization of DARPP-32 and I- 1 in the amygdala and hippocampus of the rhesus monkey. J Comp Neurol 334:1-18.
Berger B, Febvret A, Greengard P, Goldman-Rakic PS (1990): DARPP-32, a phosphoprotein enriched in dopaminoceptive neurons bearing dopamine D1 receptors: distribution in the cerebral cortex of the newborn and adult rhesus monkey. J Comp Neurol 299:327-348.

Biscotti MA, Gerdol M, Canapa A, Forconi M, Olmo E, Pallavicini A, Barucca M, Schartl M (2016): The lungfish transcriptome: a glimpse into molecular evolution events at the transition from water to land. Sci Rep 6:21571.

Brinkmann H, Venkatesh B, Brenner S, Meyer A (2004): Nuclear protein-coding genes support lungfish and not the coelacanth as the closest living relatives of land vertebrates. Proc Natl Acad Sci USA 101:4900-4905.

Buesa I, Aira Z, Azkue JJ (2016): Regulation of nociceptive plasticity threshold and DARPP-32 phosphorylation in spinal dorsal horn neurons by convergent dopamine and glutamate inputs. PLoS One 11:e0162416.

Cha JH (2007): Transcriptional signatures in Huntington's disease. Prog Neurobiol 83: 228-248.

Chen M, Zou M, Yang L, He S (2012): Basal jawed vertebrate phylogenomics using transcriptomic data from Solexa sequencing. PLoS One 7:e36256.

Csillag A, Bálint E, Adám A, Zachar G (2008): The organisation of the basal ganglia in the domestic chick (Gallus domesticus): anatomical localisation of DARPP-32 in relation to glutamate. Brain Res Bull 76:183-191.

-Domínguez L, González A, Moreno N (2015): Patterns of hypothalamic regionalization in amphibians and reptiles: common traits revealed by a genoarchitectonic approach. Front Neuroanat 9:3.

-Domínguez L, Morona R, González A, Moreno N (2013): Characterization of the hypothalamus of Xenopus laevis during development. I. The alar regions. J Comp Neurol 521:725-759.

Durstewitz D, Kröner S, Hemmings HC Jr, Güntürkün O (1998): The dopaminergic innervation of the pigeon telencephalon: distribution of DARPP-32 and co-occurrence with glutamate decarboxylase and tyrosine hydroxylase. Neuroscience 83:763-779.

-Fernández E, Schiappa R, Girault JA, Le Novère $\mathrm{N}$ (2006): DARPP-32 is a robust integrator of dopamine and glutamate signals. PLoS Comput Biol 2:e176.
Fienberg AA, Hiroi N, Mermelstein PG, Song W, Snyder GL, Nishi A, Cheramy A, O'Callaghan JP, Miller DB, Cole DG, Corbett R, Haile CN, Cooper DC, Onn SP, Grace AA, Ouimet CC, White FJ, Hyman SE, Surmeier DJ, Girault J, Nestler EJ, Greengard P (1998): DARPP-32: regulator of the efficacy of dopaminergic neurotransmission. Science 281:838-842.

-Ganz J, Kaslin J, Freudenreich D, Machate A, Geffarth M, Brand M (2012): Subdivisions of the adult zebrafish subpallium by molecular marker analysis. J Comp Neurol 520:633-655.

Glausier JR, Maddox M, Hemmings HC Jr, Nairn AC, Greengard P, Muly EC (2010): Localization of dopamine- and cAMP-regulated phosphoprotein-32 and inhibitor-1 in area 9 of Macaca mulatta prefrontal cortex. Neuroscience 167:428-438.

Goldman-Rakic PS, Muly EC 3rd, Williams GV (2000): $D_{1}$ receptors in prefrontal cells and circuits. Brain Res Brain Res Rev 31:295-301.

-González A, Morona R, Moreno N, Bandín S, López JM (2014). Identification of striatal and pallidal regions in the subpallium of anamniotes. Brain Behav Evol 83:93-103.

González A, Northcutt RG (2009): An immunohistochemical approach to lungfish telencephalic organization. Brain Behav Evol 74:4355.

González A, Smeets WJAJ (1991): Comparative analysis of dopamine and tyrosine hydroxylase immunoreactivities in the brain of two amphibians, the anuran Rana ridibunda and the urodele Pleurodeles waltlii. J Comp Neurol 303:457-477.

González A, Smeets WJAJ (1994): Catecholamine systems in the CNS of amphibians; in Smeets WJAJ, Reiner A (eds): Phylogeny and Development of Catecholamine Systems in the CNS of Vertebrates. Cambridge, Cambridge University Press, pp 77-102.

-González A, Tuinhof R, Smeets WJAJ (1993): Distribution of tyrosine hydroxylase and dopamine immunoreactivities in the brain of the South African clawed frog Xenopus laevis. Anat Embryol 187:193-201.

Greengard P (2001): The neurobiology of dopamine signaling. Biosci Rep 21:247-269. 
- Greengard P, Nairn AC, Girault J-A, Ouimet CC, Snyder GL, Fisone G, Allen PB, Fienberg A, Nishi A (1998): The DARPP-32/protein phosphatase- 1 cascade: a model for signal integration. Brain Res Rev 26:274-284.

-Gustafson EL, Greengard P (1990): Localization of DARPP-32 immunoreactive neurons in the bed nucleus of the stria terminalis and central nucleus of the amygdala: co-distribution with axons containing tyrosine hydroxylase, vasoactive intestinal polypeptide, and calcitonin gene-related peptide. Exp Brain Res 79:447458.

Halpain S, Girault JA, Greengard P (1990): Activation of NMDA receptors induces dephosphorylation of DARPP-32 in rat striatal slices. Nature 343:369-372.

-Hara M, Fukui R, Hieda E, Kuroiwa M, Bateup HS, Kano T, Greengard P, Nishi A (2010): Role of adrenoceptors in the regulation of dopamine/DARPP-32 signaling in neostriatal neurons. J Neurochem 113:1046-1059.

-Hemmings HC Jr, Girault JA, Nairn AC, Bertuzzi G, Greengard P (1992): Distribution of protein phosphatase inhibitor-1 in brain and peripheral tissues of various species: comparison with DARPP-32. J Neurochem 59:10531061.

-Hemmings HC Jr, Greengard P (1986): DARPP-32, a dopamine and adenosine3',5'-monophosphate-regulated phosphoprotein: regional, tissue, and phylogenetic distribution. J Neurosci 6:1469-1481.

-Hemmings HC Jr, Nairn AC, Greengard P (1984): DARPP-32, a dopamine- and adenosine $3^{\prime}: 5^{\prime}$-monophosphate-regulated neuronal phosphoprotein. II. Comparison of the kinetics of phosphorylation of DARPP-32 and phosphatase inhibitor 1. J Biol Chem 259: 14491-14497.

-Huang V, Hemmings HC Jr, Crews D (2014): Sociosexual investigation in sexually experienced, hormonally manipulated male leopard geckos: relation with phosphorylated DARPP-32 in dopaminergic pathways. J Exp Zool A Ecol Genet Physiol 321:595-602.

- Ishikawa M, Mizukami K, Iwakiri M, Asada T (2007): Immunohistochemical and immunoblot analysis of dopamine and cyclic AMPregulated phosphoprotein, relative molecular mass 32,000 (DARPP-32) in the prefrontal cortex of subjects with schizophrenia and bipolar disorder. Prog Neuropsychopharmacol Biol Psychiatry 31:1177-1181.

-Johansen KM, Johansen J (2006): Regulation of chromatin structure by histone H3S10 phosphorylation. Chromosome Res 14:393-404.

Kapsimali M, Vidal B, González A, Dufour S, Vernier P (2000): Distribution of the mRNA encoding the four dopamine $\mathrm{D}_{1}$ receptor subtypes in the brain of the European eel (Anguilla anguilla): comparative approach to the function of $\mathrm{D}_{1}$ receptors in vertebrates. J Comp Neurol 419:320-343.
Kuroiwa M, Bateup HS, Shuto T, Higashi H, Tanaka M, Nishi A (2008): Regulation of DARPP-32 phosphorylation by three distinct dopamine $\mathrm{D}_{1}$-like receptor signaling pathways in the neostriatum. J Neurochem 107: 1014-1026.

Langley KC, Bergson C, Greengard P, Ouimet CC (1997): Co-localization of the $D_{1}$ dopamine receptor in a subset of DARPP-32-containing neurons in rat caudate-putamen. Neuroscience 78:977-983.

Liedtke WB, McKinley MJ, Walker LL, Zhang H, Pfenning AR, Drago J, Hochendoner SJ, Hilton DL, Lawrence AJ, Denton DA (2011): Relation of addiction genes to hypothalamic gene changes subserving genesis and gratification of a classic instinct, sodium appetite. Proc Natl Acad Sci USA 108:12509-12514.

-López JM, Domínguez L, Moreno N, Morona R, Joven A, González A (2009): Distribution of orexin/hypocretin immunoreactivity in the brain of the lungfishes Protopterus dolloi and Neoceratodus forsteri. Brain Behav Evol 74: 302-322.

López JM, Domínguez L, Morona R, Northcutt RG, González A (2012): Organization of the cholinergic systems in the brain of two lungfishes, Protopterus dolloi and Neoceratodus forsteri. Brain Struct Funct 217:549-576.

López JM, González A (2015): Comparative analysis of the serotonergic systems in the CNS of two lungfishes, Protopterus dolloi and Neoceratodus forsteri. Brain Struct Funct 220:385-405.

López JM, González A (2017): Organization of the catecholaminergic system in the brain of lungfishes, the closest living relatives of terrestrial vertebrates. J Comp Neurol 525:30833109.

López JM, Morona R, González A (2010): Immunohistochemical localization of DARPP-32 in the brain and spinal cord of anuran amphibians and its relation with the catecholaminergic system. J Chem Neuroanat 40:325-338.

López JM, Morona R, Moreno N, González A (2017): The organization of the central nervous system of lungfishes: an immunohistochemical approach; in Kaas J (ed): Evolution of Nervous Systems, ed 2. Oxford, Elsevier, vol 1, pp 121-139.

Marín O, Smeets WJAJ, González A (1998): Evolution of the basal ganglia in tetrapods: a new perspective based on recent studies in amphibians. Trends Neurosci 21:487-494.

- McHenry JA, Bell GA, Parrish BP, Hull EM (2012): Dopamine D1 receptors and phosphorylation of dopamine- and cyclic AMPregulated phosphoprotein-32 in the medial preoptic area are involved in experience-induced enhancement of male sexual behavior in rats. Behav Neurosci 126:523-529.

- Meredith JM, Moffatt CA, Auger AP, Snyder GL, Greengard P, Blaustein JD (1998): Matingrelated stimulation induces phosphorylation of dopamine- and cyclic AMP-regulated phosphoprotein-32 in progestin receptorcontaining areas in the female rat brain. J Neurosci 18:10189-10195.
Metzger M, Britto LR, Toledo CA (2006): Monoaminergic markers in the optic tectum of the domestic chick. Neuroscience 141:17471760.

Moreno N, González A (2011): The non-evaginated secondary prosencephalon of vertebrates. Front Neuroanat 5:12.

-Moreno N, Morona R, López JM, González A (2010): Subdivisions of the turtle Pseudemys scripta subpallium based on the expression of regulatory genes and neuronal markers. J Comp Neurol 518:4877-4902.

Morona R, Ferrán J, Puelles L, González A (2011): Embryonic genoarchitecture of pretectum in Xenopus laevis: a conserved pattern in tetrapods. J Comp Neurol 519:1024-1050.

Morona R, Ferrán J, Puelles L, González A (2017): Gene expression analysis of developing cell groups in the pretectal region of Xenopus laevis. J Comp Neurol 525:715-752.

Nieuwenhuys R (1998): Lungfishes; in Nieuwenhuys R, ten Donkelaar HJ, Nicholson C (eds): The Central Nervous System of Vertebrates. Heidelberg, Springer, vol 2, pp 936-1006.

Nishi A, Matamales M, Musante V, Valjent E, Kuroiwa M, Kitahara Y, Rebholz H, Greengard P, Girault JA, Nairn AC (2017): Glutamate counteracts dopamine/PKA signaling via dephosphorylation of DARPP-32 Ser-97 and alteration of its cytonuclear distribution. J Biol Chem 292:1462-1476.

-Nishi A, Watanabe Y, Higashi H, Tanaka M, Nairn AC, Greengard P (2005): Glutamate regulation of DARPP-32 phosphorylation in neostriatal neurons involves activation of multiple signaling cascades. Proc Natl Acad Sci USA 102:1199-1204.

-Northcutt RG (1980): Retinal projections in the Australian lungfish. Brain Res 185:85-90.

O'Connell LA, Matthews BJ, Ryan MJ, Hofmann HA (2010): Characterization of the dopamine system in the brain of the tungara frog, Physalaemus pustulosus. Brain Behav Evol 76: 211-225.

Ouimet CC, Greengard P (1990): Distribution of DARPP-32 in the basal ganglia: an electron microscopic study. J Neurocytol 19:39-52.

-Ouimet CC, Lamantia AS, Goldman-Rakic P, Rakic P, Greengard P (1992): Immunocytochemical localization of DARPP-32, a dopamine and cyclic-AMP-regulated phosphoprotein, in the primate brain. J Comp Neurol 323:209-218.

-Ouimet CC, Langley-Gullion KC, Greengard P (1998): Quantitative immunocytochemistry of DARPP-32-expressing neurons in the rat caudatoputamen. Brain Res 808:8-12.

Ouimet CC, Miller PE, Hemmings HC Jr, Walaas SI, Greengard P (1984): DARPP-32, a dopamine- and adenosine- $3^{\prime}, 5^{\prime}$-monophosphateregulated phosphoprotein enriched in dopamine-innervated brain regions. III. Immunocytochemical localization. J Neurosci 4: 111-124. 
- Perez RG, Lewis RM (1992): Regional distribution -Sánchez-Camacho C, Marín O, González A of DARPP-32 (dopamine- and adenosine 3', $5^{\prime}$-monophosphate-regulated phosphoprotein of $\mathrm{Mw}=32,000)$ mRNA in mouse brain. J Comp Neurol 318:304-315.

- Petryszyn S, Sanchez MG, Gagnon D, Beaulieu JM, Parent A, Parent M (2017): A dense cluster of D1 + cells in the mouse nucleus accumbens. Synapse 71:51-54.

-Puelles L, Rubenstein JL (2003): Forebrain gene expression domains and the evolving prosomeric model. Trends Neurosci 26:469-476.

Puelles L, Rubenstein JL (2015): A new scenario of hypothalamic organization: rationale of new hypotheses introduced in the updated prosomeric model. Front Neuroanat 9:27.

Rajput PS, Kharmate G, Kumar U (2012): Colocalization of somatostatin receptors with DARPP-32 in cortex and striatum of rat brain. J Mol Neurosci 48:696-705.

Rajput PS, Kharmate G, Somvanshi RK, Kumar U (2009): Colocalization of dopamine receptor subtypes with dopamine and cAMP-regulated phosphoprotein (DARPP-32) in rat brain. Neurosci Res 65:53-63.

Reiner A, Laverghetta AV, Meade CA, Cuthbertson SL, Bottjer SW (2004): An immunohistochemical and pathway tracing study of the striatopallidal organization of area $\mathrm{X}$ in the male zebra finch. J Comp Neurol 469:239261.

Reiner A, Perera M, Paullus R, Medina L (1998): Immunohistochemical localization of DARPP32 in striatal projection neurons and interneurons in pigeons. J Chem Neuroanat 16:17-33.

Reiner A, Northcutt RG (1987): An immunohistochemical study of the telencephalon of the African lungfish, Protopterus annectens. J Comp Neurol 256:463-481.

Roberts TF, Hall WS, Brauth SE (2002): Organization of the avian basal forebrain: chemical anatomy in the parrot (Melopsittacus undulatus). J Comp Neurol 454:383-408.

Robra L, Thirumalai V (2016): The intracellular signaling molecule Darpp-32 is a marker for principal neurons in the cerebellum and cerebellum-like circuits of zebrafish. Front Neuroanat 10:81.

Runne H, Régulier E, Kuhn A, Zala D, Gokce O, et al. (2008): Dysregulation of gene expression in primary neuron models of Huntington's disease shows that polyglutamine-related effects on the striatal transcriptome may not be dependent on brain circuitry. J Neurosci 28: 9723-9731. (2002): Distribution and origin of the catecholaminergic innervation in the amphibian mesencephalic tectum. Vis Neurosci 19:321333.

- Schalling M, Djurfeldt M, Hökfelt T, Ehrlich M, Kurihara T, Greengard P (1990): Distribution and cellular localization of DARPP-32 mRNA in rat brain. Brain Res Mol Brain Res 7:139149.

-Schnabel R, Metzger M, Jiang S, Hemmings HC Jr, Greengard P, Braun K (1997): Localization of dopamine D1 receptors and dopaminoceptive neurons in the chick forebrain. J Comp Neurol 388:146-168.

- Scott L, Kruse MS, Forssberg H, Brismar H, Greengard P, Aperia A (2002): Selective upregulation of dopamine $\mathrm{D} 1$ receptors in dendritic spines by NMDA receptor activation. Proc Natl Acad Sci USA 99:1661-1664.

-Smeets WJAJ, López JM, González A (2001): Immunohistochemical localization of DARPP-32 in the brain of the lizard, Gekko gecko: co-occurrence with tyrosine hydroxylase. J Comp Neurol 435:194-210.

Smeets WJAJ, López JM, González A (2003): Immunohistochemical localization of DARPP-32 in the brain of the turtle, Pseudemys scripta elegans: further assessment of its relationship with dopaminergic systems in reptiles. J Chem Neuroanat 25:83-95.

Sternberger LA (1979): Immunocytochemistry. New York, Wiley.

-Stipanovich A, Valjent E, Matamales M, Nishi A, Ahn JH, Maroteaux M, Bertran-Gonzalez J, Brami-Cherrier K, Enslen H, Corbillé AG, Filhol O, Nairn AC, Greengard P, Hervé D, Girault JA (2008): A phosphatase cascade by which rewarding stimuli control nucleosomal response. Nature 453:879-884.

-Svenningsson P, Nishi A, Fisone G, Girault J-A, Nairn AC, Greengard P (2004): DARPP-32: an integrator of neurotransmission. Annu Rev Pharmacol Toxicol 44:269-296.

Svenningsson P, Tzavara ET, Liu F, Fienberg AA, Nomikos GG, Greengard P (2002):DARPP-32 mediates serotonergic neurotransmission in the forebrain. Proc Natl Acad Sci USA 99: 3188-3193.
Takezaki N, Figueroa F, Zaleska-Rutczynska Z, Takahata N, Klein J (2004): The phylogenetic relationship of tetrapod, coelacanth, and lungfish revealed by the sequences of fortyfour nuclear genes. Mol Biol Evol 21:15121524.

Tepper JM, Bolam JP (2004): Functional diversity and specificity of neostriatal interneurons. Curr Opin Neurobiol 14:685-692.

-Walaas SI, Aswad DW, Greengard P (1983): A dopamine- and cyclic AMP-regulated phosphoprotein enriched in dopamine innervated brain regions. Nature 301:69-71.

-Walaas SI, Greengard P (1984): DARPP-32, a dopamine- and adenosine- $3^{\prime}, 5^{\prime}$-monophosphate-regulated phosphoprotein enriched in dopamine-innervated brain regions. I. Regional and cellular distribution in rat brain. J Neurosci 4:84-98.

Walaas SI, Hemmings HC Jr, Greengard P, Nairn AC (2011): Beyond the dopamine receptor: regulation and roles of serine/threonine protein phosphatases. Front Neuroanat 5:50.

-Wang WW, Cao R, Rao ZR, Chen LW (2004): Differential expression of NMDA and AMPA receptor subunits in DARPP-32-containing neurons of the cerebral cortex, hippocampus and neostriatum of rats. Brain Res 998:174183.

Wullimann MF, Mueller T (2004): Teleostean and mammalian forebrains contrasted: evidence from genes to behavior. J Comp Neurol 475:143-162.

Yamamoto K, Vernier P (2011): The evolution of dopamine systems in chordates. Front Neuroanat 5:21.

- Yan L, Bobula JM, Svenningsson P, Greengard P, Silver R (2006): DARPP-32 involvement in the photic pathway of the circadian system. J Neurosci 26:9434-9438.

Yger M, Girault JA (2011): DARPP-32, Jack of all trades? Master of which? Front Behav Neurosci 5:56.

- Young D, Mayer F, Vidotto N, Schweizer T, Berth $R$, et al. (2013): Mutant huntingtin gene-dose impacts on aggregate deposition, DARPP32 expression and neuroinflammation in HdhQ150 mice. PLoS One 8:e75108.

-Yuste JE, Echeverry MB, Ros-Bernal F, Gómez A, Ros CM, Campuzano CM, Fernández-Villalba E, Herrero MT (2012): 7-Nitroindazole down-regulates dopamine/DARPP-32 signaling in neostriatal neurons in a rat model of Parkinson's disease. Neuropharmacology 63: 1258-1267. 